\title{
Economic Development and the Death of the Free Market
}

\author{
Blair Fix
}

August 20, 2021

\begin{abstract}
According to neoclassical economics, the most efficient way to organize human activity is to use the free market. By stoking self interest, the theory claims, individuals can benefit society. This idea, however, conflicts with the evolutionary theory of multilevel selection, which proposes that rather than stoke individual self interest, successful groups must suppress it.

Which theory better describes how human societies develop? I seek to answer this question by studying the opposite of the market: namely hierarchy. I find evidence that as human societies develop, they turn increasingly to hierarchical organization. Yet they do so, paradoxically, at the same time that the language of free markets becomes more common, and culture becomes more individualistic.

This evidence, I argue, contradicts free-market theory, but only if we treat it as a scientific doctrine. If instead we treat free-market theory as an ideology, the pieces come together. Free-market thinking, I speculate, may stoke the formation of hierarchy by cloaking power in the language of 'freedom'.
\end{abstract}

Keywords: hierarchy; hierarchical power; free market; economic development; sociality; cultural evolution; multilevel selection; energy

blairfix@gmail.com 


\section{Free-market theory in an evolutionary context}

There is perhaps nothing more central to mainstream economics than the belief in free markets. The idea is seductively simple. Guided only by self-interest, individuals can act through the market to benefit the whole of society. This notion of the 'invisible hand' (Smith, 1776) has become foundational to neoclassical economics. The theory proposes that in a perfectly competitive market, the autonomous actions of selfish individuals will lead to an outcome that is 'Pareto optimum' (Mas-Colell et al., 1995). In this situation, no person can be made better off without making at least one person worse off.

The neoclassical theory of free markets is not without critics. Heterodox political economists have pointed out many flaws, mostly related to the theory's unrealistic assumptions (Hunt, 2011; Keen, 2001; Keen and Standish, 2006; Lee and Keen, 2004; Means, 1992; Mirowski, 1991; Nitzan and Bichler, 2009; Pullen, 2009; Robinson, 1962; Sraffa, 1960; Veblen, 1898). My goal here, however, is not to revisit this debate, but instead to broaden it. The neoclassical theory of free markets is, at its core, a theory of how human groups should organize. It postulates that groups can organize effectively using decentralized competition, and that the selfish actions of individuals can benefit the group. Yet this theory contradicts, in almost every detail, the modern evolutionary understanding of how social organisms function.

According to the theory of multilevel selection, social organisms face a fundamental dilemma. Actions that are best for the group rarely maximize relative fitness of individuals within the group (Sober and Wilson, 1999; Wilson and Gowdy, 2015; Wilson and Sober, 1989, 1994; Wilson and Wilson, 2007). This creates a tension between the self-interest of individuals and the interest of the group. To resolve this tension, social organisms find ways to suppress the selfinterest of individuals. How they do so is an open question. But evolutionary history reveals a common trend. As groups become larger and more complex, they tend to become more hierarchical (Sec. 2).

In this evolutionary context, the theory of free markets is an outlier. It posits that, contrary to what we observe among other social organisms, humans need not suppress self-interest to organize in large groups. And we need not use hierarchical organization. We can build complex societies, the theory claims, using decentralized competition. 
My goal here is to test this claim. I look for evidence that human societies remain decentralized as they industrialize (Sec. 3). I find little evidence that this is true. Instead, the data suggests that to industrialize, human societies turn to hierarchical organization. As energy use increases, governments tend to get larger and the relative number of managers tends to grow (Sec. 3.4).

To explain this evidence, I develop a formal model of institutional hierarchy (Sec. 3.5). The model assumes that institutions are hierarchically organized, and that they grow larger as energy use increases. After validating this 'energyhierarchy' model, I use it to infer how the 'degree of hierarchy' (Sec. 3.2) within societies varies with economic development. The results are unambiguous: as societies consume more energy, they appear to become more hierarchical (Sec. 3.6).

This growth of hierarchy seems to contradict the neoclassical theory of free markets. Societies do not (as the theory claims they should) use small-scale competition to develop. Still more puzzling, I find that the growth of hierarchy may be associated with the spread of free-market ideas (Sec. 4). Looking at the United States, I find that as government grew and the number of managers increased, free-market jargon became more popular (Sec. 4.1). Moreover, international evidence suggests that cultures that are more individualistic and more tolerant of deviant behavior are, at the same time, more hierarchical (Sec. 4.3).

To make sense of this paradox, I speculate that free-market theory may actually stoke the growth of hierarchy. It does so, I propose, by treating firms (not individuals) as the unit of competition. This focus legitimizes the firm as an autonomous unit, while leaving the firm's internal structure as a 'black box'. By championing firm autonomy, free-market theory may legitimize the firm's internal chain of command, thereby justifying the accumulation of power.

If this idea is correct, it leads to a radical way of integrating free-market ideas with the theory of multilevel selection. The two schools may not be competing scientific hypotheses. Instead, neoclassical economics may be best treated as a belief system whose existence should be explained using the tools of cultural evolution. 


\section{The great debate: hierarchy vs. the free market}

Hierarchy is to free markets what light is to darkness: namely, the polar opposite. Free markets decentralize control. Hierarchies centralize it. Free markets promote autonomy. Hierarchies promote subservience. The two forms of organization, it seems, could not be more different.

Economists have long recognized this fact. But rather than study the differences between hierarchy and the market, mainstream economists have opted instead to pass judgment. The dominant school in economics - neoclassical theory - claims that outcomes from perfectly competitive markets are 'optimal', whereas outcomes from centralized control are 'inefficient' (Acemoglu and Robinson, 2001).

I find this response problematic. It is much like if biologists deemed singlecelled organisms to be 'optimal', but deemed multicellular organisms 'inefficient'. This conclusion misses the point. The two forms of life are simply different. What is interesting is not whether one form is 'better' than the other, but why the two forms of life exist, how they evolved, and where evolution is headed.

I propose that by taking this wider evolutionary perspective, we can better understand the debate between free markets versus hierarchy. The question we should ask is - what is the direction of human social evolution? Towards less hierarchy? Or towards more of it?

\subsection{Hierarchy in an evolutionary context}

Before we look at the direction of hierarchy among human societies, we should look first at the big picture. Let's review the role of hierarchy in the evolution of life on Earth.

Hierarchical structure is ubiquitous in the natural world - so much so that the social scientist Herbert Simon proposed that hierarchy is the 'architecture of complexity' (1991). The idea is that complex systems are built by merging simpler components, creating a hierarchy of sub-systems (Annila and Kuismanen, 2009). Along with this hierarchy of structure, Simon argued, comes a hierarchy of control. Complex biological systems are generally not composed of autonomous subcomponents. Instead, as complexity grows, subcomponents 
surrender autonomy to a centralized system of command and control.

The evolution of life on Earth supports Simon's idea that hierarchy is the 'architecture of complexity'. Through a series of 'major evolutionary transitions', life has grown more complex (Smith and Szathmary, 1997). Although different in form, each transition appears to obey the same principle: complex structure grows from the merger of simpler sub-units.

Life began, we presume, when organic molecules assembled into larger entities. The basic structure that emerged - and remains to this day - is that of the prokaryotic cell. In the next major transition, eukaryotic cells evolved (we believe) from the merger of two prokaryotic cells - a bacterium and an archaeon (López-García et al., 2017; López-García and Moreira, 1999; Margulis, 1981; Sagan, 1967). The bacterium became the mitochondria of modern eukaryotes, while the archaeon became the cytoplasm and nucleus. In the next transition, eukaryotic cells evolved into multicellular organisms - a symbiosis that seems to have happened multiple times (Grosberg and Strathmann, 2007). In the last major transition, solitary organisms evolved into 'eusocial' species that cooperate in large groups (Nowak et al., 2010; West et al., 2015; Wilson and Hölldobler, 2005). With their large colonies and intricate caste structure, the social insects (ants, bees, termites) are the most conspicuous example of this eusociality. Some scientists believe that modern humans may be the latest addition to the eusocial club (Gowdy and Krall, 2013, 2014; Richerson and Boyd, 1998; Turchin, 2013).

Looking at these major transitions, we see that they obey the two principles of hierarchy. First, more complex structure is built from simpler components. Second, the growth of complexity seems to involve the centralization of control.

Let's begin with the nesting aspect of hierarchy, which we see everywhere in life. Eukaryotic cells, for instance, are built from simpler organelles (i.e. the nucleus and mitochondria). Multicellular organisms, in turn, are built from simpler cells. And eusocial colonies are built from individual organisms. Each new layer of complexity, it seems, is assembled by merging simpler components.

This nested hierarchy, Herbert Simon proposes, occurs through a process of evolutionary problem solving (Herbert, 1962). Structures evolve that solve specific problems. The cell, for instance, solves the problem of separating 'living' matter from 'non-living' matter. Once this problem is solved, the newly created 
structure serves as the building block to solve new problems. Eukaryotic cells built on the structure of prokaryotes to solve a new problem - one of energetics. When bacterium evolved into eukaryotic mitochondria, they shed most of their DNA, freeing up more energy for protein synthesis (Lane, 2011; Lane and Martin, 2010). This free energy may be what allowed eukaryotes to grow more complex than their prokaryotic counterparts (Lane, 2014, 2015).

In addition to hierarchy in the 'nesting' sense, the evolution of life also follows the principle of hierarchy in the sense of centralized control. Large, complex organisms are not composed of autonomous units. Instead, the growth of complexity seems to involve the gradual loss of autonomy among sub-units, and the growth of centralized control. The eukaryotic cell, for instance, is not composed of autonomous organelles. Instead, sub-units are governed by a 'command and control center' - the nucleus (Pennisi, 2004). Similarly, multicellular animals have evolved centralized control in the form of the nervous system (Arendt et al., 2008). Eusocial insects have elaborate caste systems in which most individuals surrender their reproductive capacity to a single queen (although the queen does not, in turn, directly control workers) (O'Donnell, 1998; Shimoji et al., 2014). Humans (who are possibly the latest eusocial species) also organize using hierarchy. Evidence suggests that as societies become more populous, they add new layers of administrative hierarchy (Turchin, 2010; Turchin and Gavrilets, 2009).

The use of centralized control may arise for two (related) reasons. First, assembling a larger system from many smaller components requires coordination. Although decentralized coordination may be possible, it seems that organization within (and among) living things usually involves some degree of centralization.

Second, there is the problem of the 'self-interest' of sub-units. The major evolutionary transitions happened by merging sub-units that were previously autonomous. According to the theory of multilevel selection, this merger is not possible unless the 'self-interest' of sub-units is suppressed (Okasha, 2005; Wilson, 1997; Wilson et al., 2008). That is because there is often an evolutionary conflict between the 'interest' of the group versus the 'interest' of individuals within the group (Sober and Wilson, 1999; Wilson and Gowdy, 2015; Wilson and Sober, 1989, 1994; Wilson and Wilson, 2007). ${ }^{1}$

\footnotetext{
${ }^{1}$ Note that the words 'interest' and 'self-interest' do not indicate intent. Rather, they are a Darwinian metaphor for actions that increase relative 'fitness' (differential reproduction). Also, multilevel selection theory notes that the 'suppression' of self interest (when it occurs) is always partial and never complete.
} 
To understand this conflict, recall that natural selection rewards differential reproduction - what biologists call 'fitness'. In many scenarios, what is 'fit' for individuals is not 'fit' for the group. Take human warfare as an example. For the group (an army), it is best if all soldiers charge into battle cohesively. But for an individual within the group, the best strategy is to run away from the frontline (Fix, 2019b).

So here we have a conflict between levels of selection. By deserting, an individual soldier can reduce their chance of death (hence, increase their fitness). However, if too many soldiers desert, the army collapses (hence, the group's fitness decreases). To succeed in battle, the group must therefore suppress the self-interest (relative fitness) of deserters. ${ }^{2}$

\section{Multilevel vs. gene-centric selection}

The theory of multilevel selection argues that successful groups must suppress natural selection at lower levels of organization. Since this claim remains controversial, it is worth discussing problems with the alternative view. According to orthodox Darwinism, all aspects of evolution can be reduced to competition between genes.

Popularized by Richard Dawkins (1976), the gene-centric argument is convincingly simple. If an organism outbreeds its competitors, the organism's genes also win. It seems, therefore, that higher levels of selection are not needed to explain the evolution of organized groups. Instead, complex structure arises solely from the 'self-interest' of genes.

While at first convincing, this argument makes a subtle philosophical mistake. It assumes that a successful reduction (breaking a system into parts) implies a successful resynthesis (using the parts to rebuild the system). Often, however, reduction is a one-way street. Given a complex system, we can break it into parts. But we cannot take the parts (alone) and rebuild the system.

As an example of this asymmetry, consider human travel. If I board an airplane to Tokyo, we know that the atoms in my body did the same thing. To paraphrase Richard Feynman, we can state unequivocally that 'everything that

\footnotetext{
${ }^{2}$ Armies often suppress the motive to desert by making it a capital crime. The certain threat of capital punishment makes the possible threat of battlefield death the lesser of two evils.
} 
I do, my atoms do'. ${ }^{3}$ Unfortunately, this reduction tells us nothing about why I went to Tokyo. It turns out that I had a job interview — something that is easy to understand by looking at a higher level of organization (the individual). But if we try to derive 'job interviews' from atomic physics, we will get nowhere.

The same principle holds in evolution. We can always reduce evolution to competition among genes. Often, however, we cannot start with genes (alone) and resynthesize the evolution of higher-level structure. Interestingly, this asymmetry is evident in Richard Dawkin's exposition of gene-centric theory. He notes that organisms are 'vehicles' for genes. But he does not explain how these vehicles came to exist.

On that front, how did multicellular organisms evolve? From the gene's eye view, we are faced with a paradox. Given atomistic competition between cells, one would expect that natural selection would suppress the evolution of multicellularity, and instead favor the evolution of cancer. That is because cancerous cells outreproduce normal cells. Cancer should therefore be favored by natural selection. So multicellularity (as we know it) should not exist.

Since multicellular organisms do exist, this logic must have a flaw. To see it, however, we need to leave the gene's eye view and instead look at higher levels of selection. When cells began to organize in groups, selection at the multicellular level began to override selection at the cell level. That created pressure to suppress cancer. The reason is simple: cancer tends to kill multicellular organisms. Hence at the organism level, cancer is selected against. This higher-level selection allowed mechanisms (such as the immune system) to evolve that suppress somatic (cell-level) evolution (Aktipis, 2016). In this light, cancer is not a 'disease' so much as a failure of the organism - a "failure of multicellular systems to suppress somatic evolution" (Nedelcu, 2020).

To wrap up this discussion, orthodox Darwinism reduces evolution to the spread of genes - something that can always be done in hindsight. In contrast, multilevel selection theory tries to resynthesize complex systems by understanding the tug-of-war between different levels of selection. The key insight of multilevel selection theory is that high-level organization requires high-level selection that suppresses selection at lower levels. Among multicellular animals,

\footnotetext{
${ }^{3}$ Speaking about the importance of the atomic theory of matter as the basis of other fields, Richard Feynman remarked: "The most important hypothesis in all of biology, for example, is that everything that animals do, atoms do" (Feynman et al., 2013, emphasis in original).
} 
organism-level selection suppresses cell-level selection. And among social animals, group-level selection suppresses individual-level selection.

\section{Hierarchy as a tool for suppressing lower-level selection}

Multilevel selection theory does not specify the mechanisms that suppress lower levels of selection. But the properties of biological systems suggest that hierarchy may be a common solution.

Looking at the major evolutionary transitions, John Stewart argues that successful groups suppress lower levels of selection by turning to top-down 'management' (Stewart, 2019a,b, 2020). In this sense, large-scale organization (whether of molecules, cells, or organisms) is accomplished by integrating subunits into a hierarchical control structure.

Whether complex organization requires hierarchy is an open question. But it does seem that complexity and hierarchy go hand in hand.

\subsection{A clash of theories: To suppress or stoke self-interest}

The major transitions in evolution suggest that hierarchy is an important tool for organizing complex living systems. Might the same principle be true in human societies? If so, then as societies become more complex, they should also become more hierarchical.

Returning to economics, this evolutionary prediction puts free-market theory on its head. That's because according to the neoclassical theory of free markets, hierarchy is unnecessary for group organization. Instead, neoclassical theory argues that humans can organize effectively without any form of centralized control. All that is needed is a competitive market.

To arrive at this conclusion, neoclassical theory argues that groups can organize by stoking self-interest. If each person acts selfishly, they will be led 'as if by an invisible hand' to benefit the whole society. First proposed by Adam Smith (1776), this idea is now a central tenet of mainstream economics, formalized in the 'first fundamental theorem of welfare economics'. The theorem claims that under conditions of perfect competition (in which all firms are 'price takers'), markets will allocate resources in a way that is 'Pareto efficient' (Mas-Colell 
et al., 1995). In this situation, no person can be made better off without making at least one person worse off.

With their welfare theorem in hand, neoclassical economists look at hierarchical organization and see an 'inefficient' system. Yet when biologists look at the same system, they see an 'effective' group-level adaptation. So it seems that we have a clash of theories.

Given this clash, it is easy to get bogged down in debates about which form of organization (hierarchy or market) is 'best'. I think that is a mistake. Instead, we should ask an a priori question: when it comes to human social evolution, what is the trend? Towards less hierarchy? Or more?

\section{The growth of hierarchy with economic development}

To shed light on the debate between economic theory and evolutionary theory, I attempt to measure how human social hierarchy varies with economic development. Ideally, we could study this variation in three steps:

1. Postulate a measure of social hierarchy

2. Apply this measure to human society

3. See how hierarchy varies with economic development

In principle, this method is straightforward. We treat human relations as a network, and then measure the structure of this network. The more 'tree-like' the network structure, the greater the 'degree of hierarchy'.

While simple in principle, this straight-ahead approach is difficult in practice. The problem is that the relevant data - the network structure of an entire society - does not exist. Yes, we have data for many social networks, especially those on modern social media. But this data is insufficient for the task I propose. Instead, what we need is detailed information about the chain of command within every firm and every level of government. It is these formal work relations, I argue, that are most important for measuring the hierarchical structure of society.

Unfortunately, we do not have this chain-of-command information - not for a single country, let alone many. Given this lack of data, how can we proceed? 
My solution is to use an indirect approach:

1. Postulate a metric of social hierarchy

2. Apply this metric to human society by simulating the required data

3. Infer how hierarchy varies with economic development

The difference here is in step 2. Rather than using direct data for the network structure of society (which does not exist), I use an evidence-based model to simulate this data.

Here, then, is the road ahead. After clarifying my choice of social network (Sec. 3.1), I outline two metrics of hierarchy (Sec. 3.2). I then discuss how I measure 'economic development' (Sec. 3.3). Next, I look at empirical trends that plausibly relate to social hierarchy (Sec. 3.4). I then use this evidence to build a formal model of how social hierarchy varies with economic development (Sec. 3.5). Finally, I use this 'energy-hierarchy model' to simulate the network structure of real-world societies. The result is a model-based inference of how hierarchy varies with economic development (Sec. 3.6).

\subsection{Which social network to measure}

To investigate how social hierarchy varies with economic development, we must first define the social network we want to quantify. Since humans form many types of social relations, there are a variety of ways to define this network. (Some possibilities include networks of family, friends, social media followers, colleagues, travel, trade, etc.) How should we decide which network is relevant?

Since my focus is on hierarchy as it applies to neoclassical economics, it is this theory that (rightly or wrongly) defines the social network of interest. In neoclassical economics, there are two basic units of organization - one for 'production' and one for 'consumption'. Production is done by firms. Consumption is done by consumers. The loose network that binds these two forms of organization is called the 'market'.

Now here is what interests me. Between these two units of organization (firms and consumers), there is an asymmetry. Consumers are individuals. But firms are groups. Even more interesting is the fact that in neoclassical theory, the internal structure of firms goes undescribed. Firms are treated as 'black boxes' - 
featureless organizations defined only by their inputs and outputs. This asymmetry leads to two questions:

1. Why is the default unit of production the firm, not the individual?

2. Why is the internal structure of firms left undescribed?

The first question has a simple answer. Economists focus on firms (as a unit of production) because this is simply how humans organize. While it is conceivable to have capitalism without firms, such a society has never existed. So economists take the real-world as a given. Firms exist.

This practical response, however, leads to more questions. Why do firms exist? To answer this question, we need to open up the firm. Yet neoclassical economics refuses to do so. Why? The answer, I believe, is sociological. When you open up a firm, you realize that it is not a market. It is a hierarchy (Leibenstein, 2013; Marglin, 1974).

It is by studying this hierarchical structure of firms (and governments) that I propose we measure the 'degree of hierarchy' in human society. Think of firms as islands of hierarchy in a free-market sea. If firms did not exist, all business relations would be organized via the market. Hence there would be no hierarchy. But as firms (and governments) emerge and grow larger, we find islands of hierarchy within the market. It is this patchwork of firm and governmental hierarchy that I wish to quantify.

\subsection{Measuring the degree of hierarchy}

To measure variation in social hierarchy, we need a way to quantify the 'degree of hierarchy' in a network. I use two different metrics:

1. the concentration of hierarchical power (CHP)

2. global reaching centrality (GRC)

Before describing these metrics, it is worth visualizing what a simple hierarchy looks like. As illustrated in Figure 1, a hierarchy is a type of network that has a tree-like structure. The more a network converges to this tree-like structure, the greater its degree of hierarchy. 


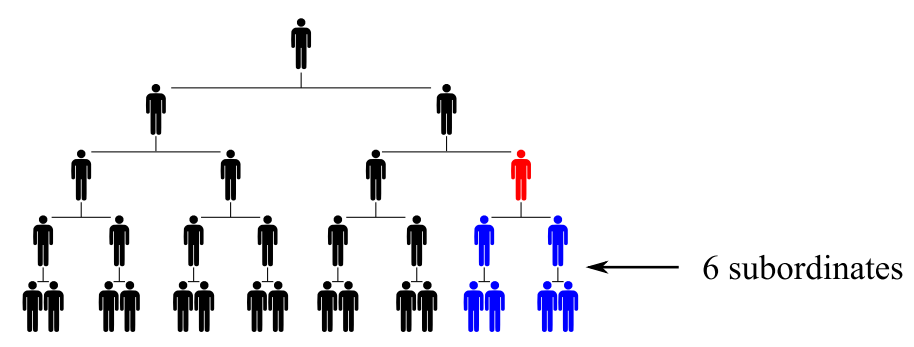

Figure 1: A social network with a hierarchical structure

As illustrated here, a hierarchy is a form of network that has a tree-like structure. In a human hierarchy, this network delineates a chain of command, in which 'superiors' command 'subordinates'. As one moves up the hierarchy, the total number of subordinates under one's control tends to increase. Here, for instance, the red individual has 6 subordinates in total. The leader of the hierarchy, in contrast, has 30 subordinates.

\section{The concentration of hierarchical power (CHP)}

In a hierarchy, decision-making authority flows from the top down. The result is that individuals at the top of the hierarchy have more power than those at the bottom - they have more ability to impose their will upon others (Bendix, 1998).

The concept of 'power' provides a way to quantify the degree of hierarchy in a social network. We start by noting that within a network, an individual's power increases as they accumulate more subordinates (people who obey their command). I propose that the distribution of control over subordinates indicates the 'degree of hierarchy' in the network. The idea is simple. When no one has any subordinates, there is no hierarchy. But when a few individuals have many subordinates, the network is extremely hierarchical.

With this thinking in mind, I use the concentration of 'hierarchical power' as a measure of the degree of hierarchy. I start by defining 'hierarchical power' as an individual's control over subordinates. Formally, the hierarchical power $(P)$ of the $i$ th person in a network is proportional to the total number of subordinates $\left(N_{s}\right)$ they control:

$$
P(i)=N_{s}(i)+1
$$

I add ' 1 ' to the number of subordinates to symbolize that all individuals retain 
control of at least one person — themselves.

For an example calculation, let's return to Figure 1. Here the red individual has 2 direct subordinates and 4 indirect subordinates. With 6 subordinates in total, this person has a hierarchical power of $P=7$. Individuals higher up the hierarchy have still more power. In Figure 1, the leader of the hierarchy has 30 subordinates, giving a hierarchical power of $P=31$.

Having defined the hierarchical power of an individual, we can apply this measure to everyone in a network. The result will be a distribution of hierarchical power. We can then use this distribution to quantify the 'degree of hierarchy'. The more concentrated the distribution of hierarchical power, the more hierarchical the network.

To measure the concentration of hierarchical power, I use the Gini index a standard measure of inequality. Formally, the 'concentration of hierarchical power' (CHP) is the Gini index of the hierarchical power $(P)$ of all $N$ individuals in a network:

$$
C H P=G\left(P_{1}, P_{2}, \ldots, P_{N}\right)
$$

The CHP varies between 0 (no hierarchy) and 1 (absolute hierarchy). As an example, the network in Figure 1 has $C H P=0.57$, indicating that it is quite hierarchical. ${ }^{4}$

\section{Global reaching centrality (GRC)}

Another approach to measuring hierarchy is to define something called 'global reaching centrality' (Mones et al., 2012; Nepusz and Vicsek, 2013). When applied to human networks, this metric again involves counting subordinates. To measure 'global reaching centrality', we first define 'local reaching centrality' $\left(C_{R}\right)$. This is the number of subordinates $N_{s}$ controlled by the $i$ th individual, expressed as a portion of the total number of other people $(N-1)$ in the network:

$$
C_{R}(i)=\frac{N_{s}(i)}{N-1}
$$

\footnotetext{
${ }^{4}$ Note that because the minimum hierarchical power is defined to be 1 (not 0 ), the concentration of hierarchical power can never be exactly 1 .
} 
Returning to Figure 1 , let's calculate $C_{R}$ for the red individual. This person has 6 subordinates within a network of $N=31$ people. Their local reaching centrality is therefore $C_{R}=6 / 30=0.2$.

The 'global reaching centrality' (GRC) of the network is then defined as the sum of the differences between the local reaching centrality of each person and the maximum reaching centrality $\left(C_{R}^{\max }\right)$ of the network:

$$
G R C=\frac{\sum_{i=1}^{n}\left[C_{R}^{\max }-C_{R}(i)\right]}{N-1}
$$

The GRC can range from 0 (no hierarchy) to 1 (absolute hierarchy). As an example, the network in Figure 1 has a $G R C=0.92$, suggesting that it is quite hierarchical.

\subsection{Measuring economic development}

Having defined how I measure hierarchy, I turn now to how I measure economic development. When economists speak of 'development', they usually mean the growth of 'real GDP'. In this paper, however, I use a different metric. I measure economic development in terms of energy use per person.

I have two reasons for using energy to measure development. First, there are many 'aggregation problems' inherent in the calculation of real GDP (Fix, 2019a; Fix et al., 2019). These problems occur largely (but not exclusively) because real GDP is based on the unit of prices, which are unstable. This instability introduces ambiguity in the value of real GDP.

Second, I use energy consumption to measure 'economic development' because I want a method that generalizes beyond human societies. If the growth of human hierarchy is an extension of a general evolutionary process, then we want a metric of 'development' that is universal. Since real GDP has no meaning outside the human economy, it is not helpful. Energy, however, is a 'universal currency' in the natural sciences (Chaisson, 2005).

The importance of energy stems from basic thermodynamics. It is the flow of energy that makes complex structure possible. Without energy flows, natural systems converge to equilibrium - a state where nothing happens on the macro scale. But when there is an energy gradient, macro-level structures tend 
to emerge - structures that dissipate energy more rapidly (Kondepudi and Prigogine, 1998).

A convection cell, driven by a temperature gradient within a fluid, is a simple example of such a 'dissipative structure'. Living organisms are a more complex example, driven by the energy flow from the sun (Annila and Annila, 2008; Boltzmann, 2011; Chaisson, 2002; Schrodinger, 1992). The human economy is still more complex, but obeys the same principle. It is a dissipative structure driven by flows of energy (Georgescu-Roegen, 1971; Giampietro et al., 2012).

Because of its role in driving complex systems, I use energy consumption as a measure of economic development. ${ }^{5}$

\subsection{Evidence for the growth of hierarchy}

My goal is ultimately to use my metrics of hierarchy (Sec. 3.2) to measure how the 'degree of hierarchy' varies with economic development. Unfortunately, the data needed to achieve this goal does not yet exist. As such, I will take an indirect route to measuring hierarchy.

I will first review evidence suggesting that hierarchy varies with economic development. In the section that follows, I show that as societies use more energy, governments tend to get larger and the number of managers tends to increase. I then use this evidence to build a formal model of hierarchy (Sec. 3.5), which I use to infer how the 'degree of hierarchy' varies with economic development (Sec. 3.6).

\section{The size of government}

In neoclassical economics, government is a necessary evil. It is a form of hierarchical organization that must exist, but should not grow too large.

Government must exist, Milton Friedman observes, to "do something that the market cannot do for itself, namely, to determine, arbitrate, and enforce the rules of the game" (1962). But while government is a prerequisite for markets,

\footnotetext{
${ }^{5}$ If one is skeptical of this choice, note that there is strong correlation between energy use and real GDP (Brown et al., 2011). As such, should we measure economic development using real GDP, the results in this paper would likely remain unchanged.
} 
it is also the market's enemy. That is because, as Franklin Fisher notes, "the principal policy insight of economics [is] that a competitive price system produces desirable results and that government interference will generally lead to an inefficient allocation of resources" (1987).

In neoclassical theory, then, government is a necessary form of hierarchy, but one that should remain as small as possible. It seems, however, that real-world societies do not listen to this 'small government' principle. Instead, economic development goes hand in hand with larger governments.

Figure 2 shows the evidence across (and within) countries. I plot here the employment share of government as it relates to energy use per capita. ('Government' is defined as the entire public sector. Each line in Fig. 2 represents the path through time of a specific country.) While country-level trends vary, the overall pattern is clear. As energy use increases, governments tend to get larger.

From a neoclassical standpoint, this result is unexpected. If markets are 'efficient', why does economic development involve government encroachment on the private sector? One possibility is that governments are not heeding economists' advice, and that societies would be better off if government remained small. If so, then it is politics that are driving the growth of government.

To investigate the role of politics, let us turn to Figure 3. Here I replot the data from Figure 2, but this time I differentiate between two types of countries:

1. Countries that have (or once had) a communist government

2. Countries that have never had a communist government

It is easy to see the difference between the two types of countries. Those that have had communist regimes tend to have larger governments than those that have not. ${ }^{6}$

Given the intense 20th-century battle between capitalism and communism, it is unsurprising that politics affect the size of government. What is surpris-

\footnotetext{
${ }^{6}$ On a historical note, the data in Figure 3 captures the collapse of the Soviet Union in action. The data begins in 1990, just when the Soviet Union disbanded. Former Soviet states like the Ukraine, Estonia, Moldova and Armenia begin (in 1990) with almost 100\% government employment - a relic of their communist history. But over the next decade, governments in these countries shrank drastically, collapsing to levels similar to their non-communist counterparts. With this government collapse came a decline in energy use.
} 


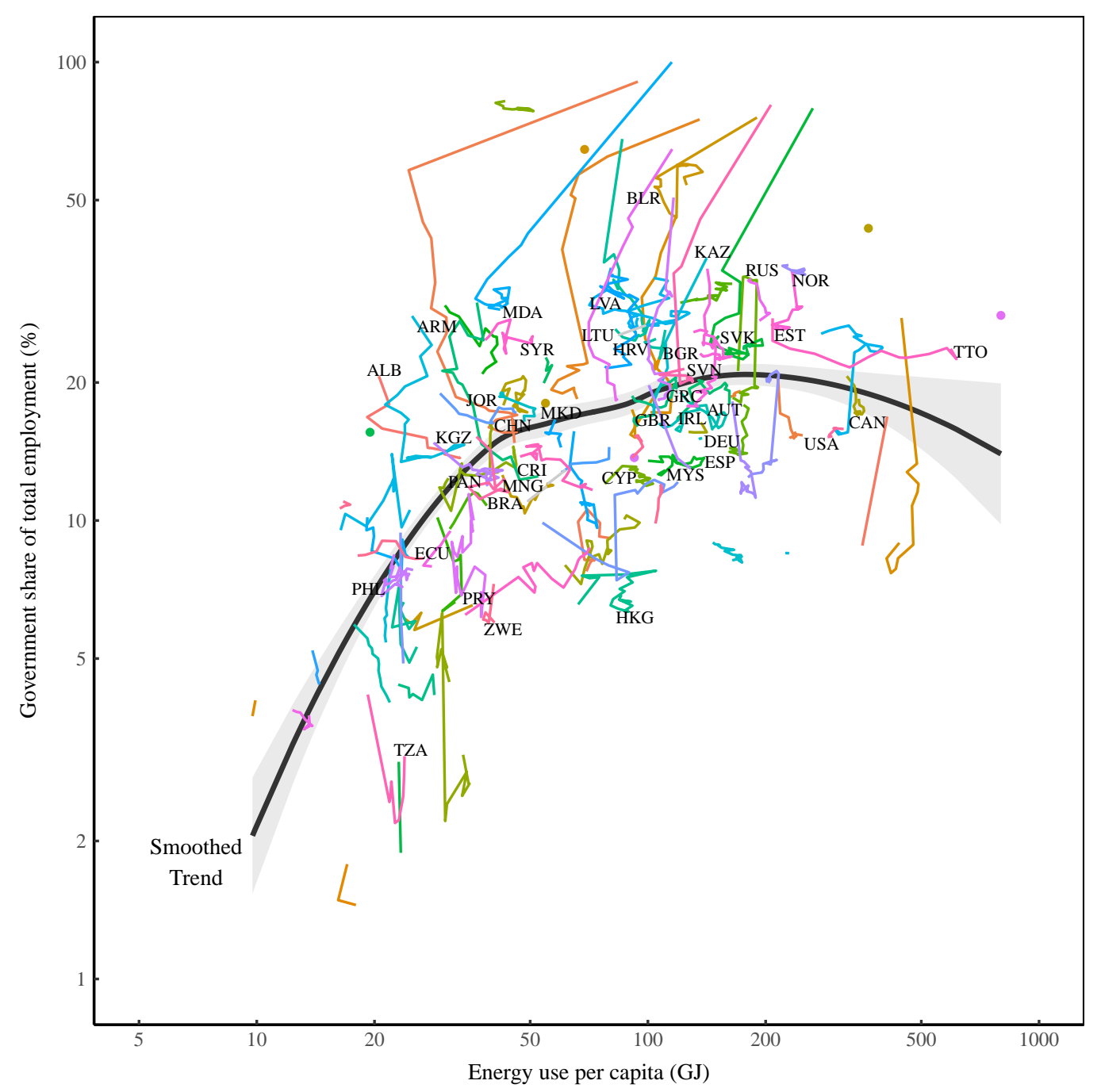

Figure 2: Government's share of employment vs. energy use per capita

I define 'government' here as employment in the entire public sector. Lines represent the path through time of individual countries (from 1990 to the present). Points represent countries with a single observation. Select countries are labeled with alpha-3 codes. The black line shows the trend across all countries, smoothed with a LOESS regression. For data sources, see Section 6. 


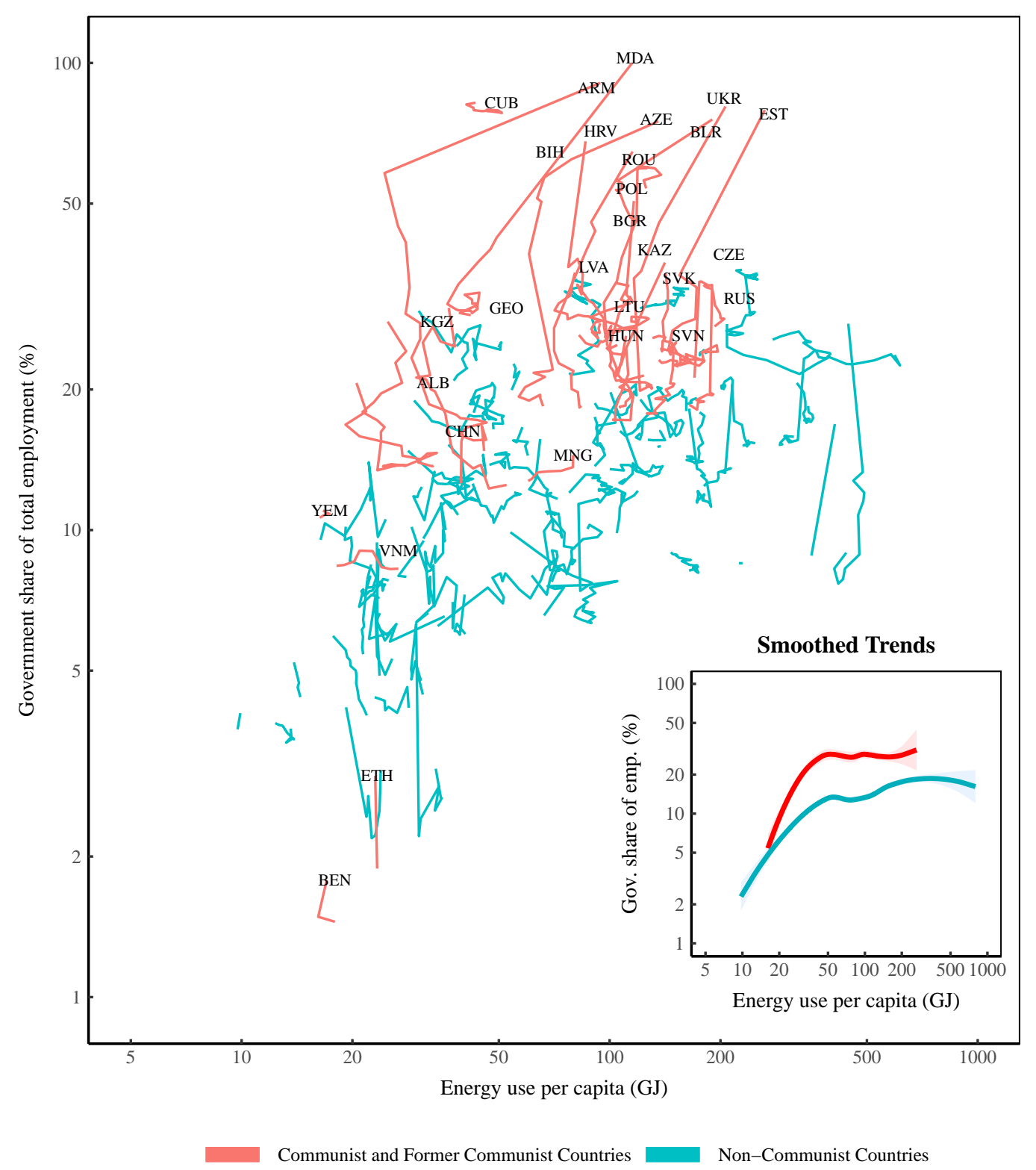

Figure 3: Government's share of employment vs. energy use per capita by political spectrum

I reproduce here the data in Fig. 2, but now distinguish between communist and noncommunist countries. 'Communist countries' are those that have (or once had) a communist regime. Lines represent the path through time of individual countries. Communist countries are labeled with alpha-3 codes. The inset panel shows the smoothed trends, calculated with a local polynomial regression. For data sources, see Section 6 . 
ing, however, is that regardless of politics, governments tend to get larger as energy use increases. The inset panel in Figure 3 shows this fact. Here I smooth the raw data (within each type of country) using a local polynomial regression. The results are interesting. In both communist and non-communist countries, governments tend to grow larger with energy use.

So yes, politics do affect the size of government. But there is also a secular trend that is independent of political ideology - a fact that does not sit well with the neoclassical theory of free markets. As societies develop, government tends to grow larger.

\section{The number of managers}

Let's turn now from the public sector to the whole economy. When describing the economy, neoclassical economists see competition between firms. But what about within firms? There, competition seems less salient. Once an employee has a position within a firm, they are expected to cooperate with their coworkers. And that usually involves taking and/or giving orders - a sign of hierarchy.

If we were to grossly simplify the structure of a firm's hierarchy, we might reduce it to two classes: those who take orders and those who give orders. The order givers are usually called managers. Their job is to command the activity of other people - a job that is unique to hierarchies. I propose, then, that the relative number of managers in a society provides a window into the degree of hierarchy. A society with no managers has no hierarchy. A society with many managers has lots of hierarchy.

With this thinking in mind, Figure 4 plots the evidence. Here, I look at how the relative number of managers (within countries) varies with energy use per capita. As with the size of government, I find that the number of managers tends to increase with economic development.

This evidence seems to contradict the neoclassical theory of free markets. As societies develop, they turn increasingly to top-down management. It could be, though, that this trend is ultimately political. In that case, politics induce the growth of hierarchy, which then 'distorts' free-market efficiency.

To investigate the role of politics, let us look at Figure 5. Here I replot the trend between the number of managers and energy use per capita. But this 


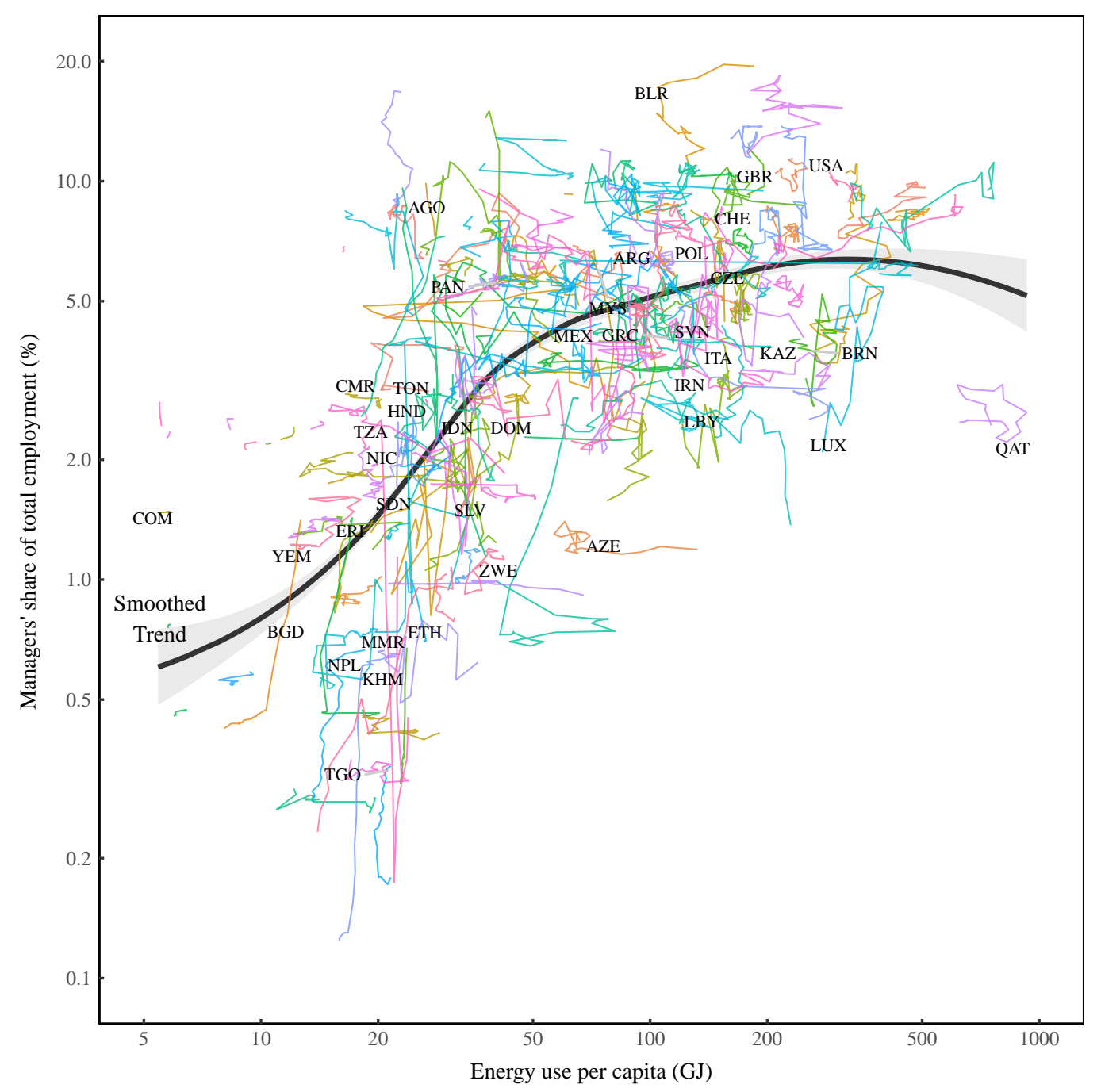

Figure 4: Managers' share of employment vs. energy use per capita

I plot here the international trend between the number of managers in a country (as a share of total employment) and energy use per capita. Lines represent the path through time of individual countries (from 1990 to the present). I have labeled select countries with alpha- 3 codes. The black line shows the trend across all countries, smoothed with a LOESS regression. For data sources, see Section 6. 


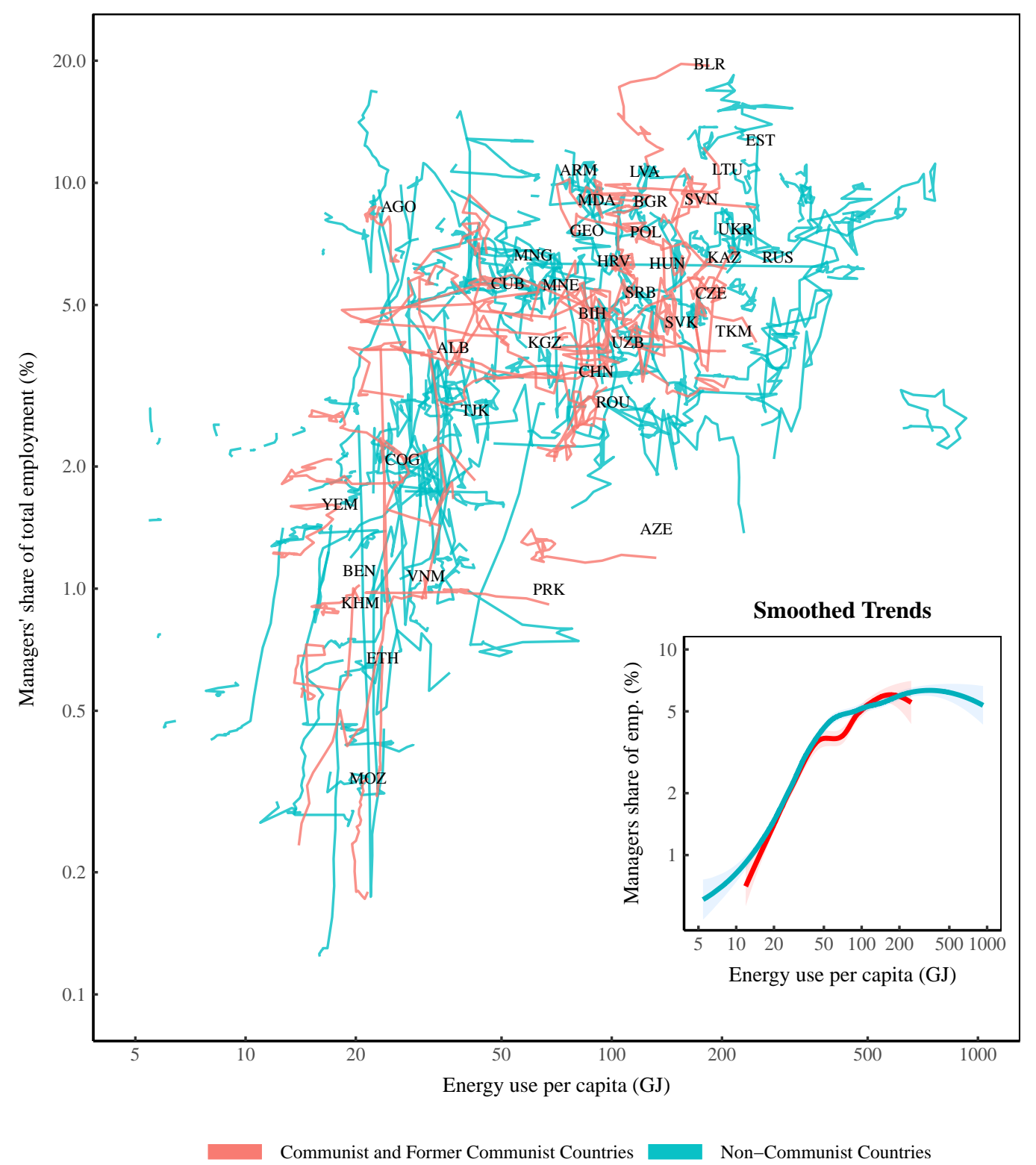

Figure 5: Managers' share of employment vs. energy use per capita by political spectrum

I reproduce here the data in Fig. 4, but now distinguish between communist and noncommunist countries. 'Communist countries' are those that have (or once had) a communist regime. Lines represent the path through time of individual countries. Communist countries are labeled with alpha-3 codes. The inset panel shows the smoothed trends, calculated with a local polynomial regression. For data sources, see Section 6 . 
time I differentiate between communist/non-communist politics. The results are telling. Unlike with the size of government, politics seem to have no effect on the number of managers. The inset panel in Figure 5 emphasizes this nondistinction. Here I show the smoothed trend across countries, differentiated by political regime. There is virtually no difference between communist and noncommunist countries. So whatever is driving the growth of managers, it is not overtly political.

\subsection{An energy-hierarchy model}

As societies consume more energy, governments tend to get larger and the number of managers increases. This evidence hints that economic development involves the growth of hierarchy.

To gain more insight into these changes, I now develop a formal model of how social hierarchy varies with energy consumption (my measure of economic development). The model is based on two assumptions:

1. Human institutions are hierarchically organized

2. These institutions tend to grow larger as energy use increases

I first formalize these assumptions into a numerical model of how social hierarchy changes with energy consumption. Then I use the model to predict how the size of government and the number of managers should grow with energy use.

\section{The Simon-Lydall model of hierarchy}

A half century ago, Herbert Simon (1957) and Harold Lydall (1959) independently developed a model of the hierarchical structure of firms. In this model, hierarchies have a fixed 'span of control', meaning all superiors control the same number of subordinates. I will call this the 'Simon-Lydall' model of hierarchy'.

When Simon and Lydall first proposed the model, little was known about how firms were actually structured. Today, we know more about firm hierarchies, and we can say that Simon and Lydall were on the right track. While the span of control is not actually constant in real-world firms, assuming it is constant is 
A flat hierarchy

(span of control $=5)$

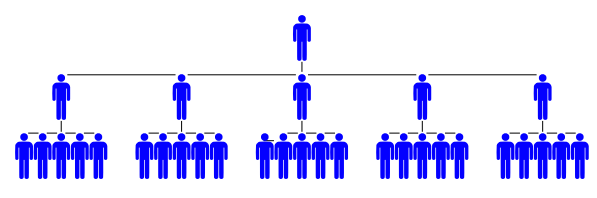

31 members
A steep hierarchy

(span of control $=2$ )

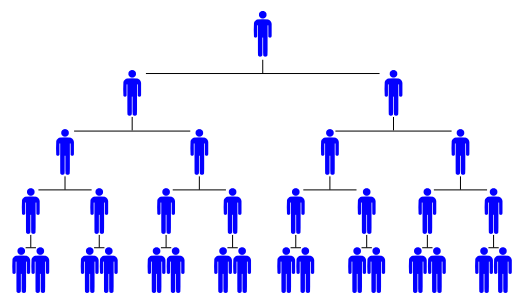

31 members

Figure 6: The 'Simon-Lydall' model of hierarchy

I show here two examples of the Simon-Lydall model of hierarchy. The model assumes that the span of control (the number of direct subordinates controlled by each superior) is constant within a given hierarchy. The span then determines the hierarchy's 'shape'. A large span creates a 'flat' hierarchy — one with relatively few hierarchical ranks (left). A small span creates a 'steep' hierarchy that has many ranks (right).

a reasonable simplification. ${ }^{7}$

To get a sense for the Simon-Lydall model of hierarchy, let's look at Figure 6. Here I visualize two modeled hierarchies, each with 31 members. The 'shape' of the hierarchy is determined by the span of control (which is fixed within the hierarchy). When the span is large (left), the hierarchy is 'flat'. When the span is small (right), the hierarchy is 'steep'.

The Simon-Lydall model has 3 equations. (For their derivation, see Section 6.) Consider a hierarchy with span of control $s$ that has $N_{T}$ members. The number of ranks $(n)$ in the hierarchy is:

$$
n=\left\lfloor\frac{\log \left[1+N_{T}(s-1)\right]}{\log (s)}\right\rfloor
$$

Here \lfloor\rfloor denotes rounding down to the nearest integer. Next, we define the number of people in the bottom hierarchical rank as:

\footnotetext{
${ }^{7}$ For case studies of firm hierarchy, see Audas et al., 2004; Baker et al., 1993; Dohmen et al., 2004; Grund, 2005; Lima, 2000; Morais and Kakabadse, 2014; Treble et al., 2001. For aggregate studies of firm hierarchy, see Ariga et al., 1992; Bell and Van Reenen, 2012; Eriksson, 1999; Heyman, 2005; Leonard, 1990; Main et al., 1993; Mueller et al., 2016; Rajan and Wulf, 2006; Tao and Chen, 2009. For a summary of these studies, see the Appendices in Fix, 2018, 2019c.)
} 


$$
N_{1}=N_{T}\left(\frac{1-1 / s}{1-1 / s^{n}}\right)
$$

Given membership in the bottom rank $\left(N_{1}\right)$, we then build the hierarchy from the bottom up. The size of each consecutive hierarchical rank $h$ (where increasing $h$ denotes moving up the hierarchy) is a function of the span of control:

$$
N_{h}=\left\lfloor\frac{N_{1}}{s^{h-1}}\right\rfloor
$$

Together, equations 5-7 define the organizational hierarchy in the SimonLydall model. They take inputs of hierarchy size $N_{T}$ and span of control $s$, and return values for the number of members $N_{h}$ in each hierarchical rank.

\section{Modeling managers}

Within the Simon-Lydall model, individuals are defined only by their rank. As such, there is no clear distinction between managers and non-managers.

To create such a distinction, I assume there is a rank threshold that divides these two classes. I define everyone in and above hierarchical rank 3 as a 'manager'. Everyone else is a 'non-manager'. The idea here is that people in the bottom rank are 'shop floor' workers. People in the second rank are 'working supervisors' (Strauss, 1957). Everyone else is a professional manager. Figure 7 shows an example of this management model.

Given this definition of 'managers', we can define the management share of employment within a hierarchy. This is the number of managers $(M)$ expressed as a fraction of hierarchy size $\left(N_{T}\right)$. In a hierarchy with $n$ ranks and span of control $s$, the management share of employment is:

$$
\frac{M}{N_{T}}=\frac{1-s^{n-2}}{1-s^{n}}
$$

Note that as the number of hierarchical ranks grows large $(n \rightarrow \infty)$, the management share of employment approaches an asymptote of $1 / s^{2}$. 


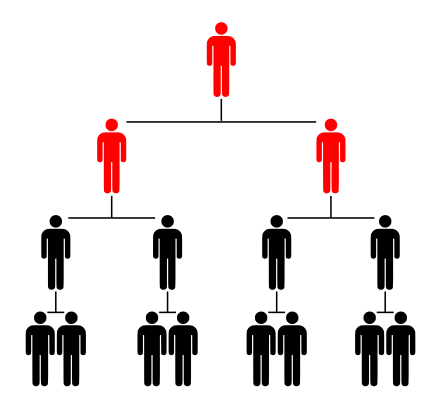

i Non-Manager i Manager

\section{Figure 7: Managers in the Simon-Lydall model}

I model 'managers' as everyone in hierarchical rank 3 and up. Everyone else is a 'nonmanager'.

\section{Energy and the size distribution of institutions}

The Simon-Lydall model takes as an input the size of an institution and returns the simulated hierarchical structure. To apply the model to a society, we must therefore know both the size distribution of institutions, and how this distribution varies with energy use.

As a first approximation, the size distribution of institutions follows a power law (Axtell, 2001; Gaffeo et al., 2003) that varies with energy use per capita (Fix, 2017). Figure 8 illustrates this fact. In the main panel, I plot the average size of firms (within countries) against energy use per capita. It is clear that as societies use more energy, firms tend to get larger. The inset panel in Figure 8 shows how this change occurs. Here I plot the size distribution of firms as a function of energy use. I group countries of the world by energy-use quartile, and then plot the aggregate size distribution of firms within each group. As energy use increases, the firm size distribution gets a fatter tail.

I model the size distribution of firms as a power law, where the probability of finding a firm with $N$ members is:

$$
p(N) \propto \frac{1}{N^{\alpha}}
$$

Here, the parameter $\alpha$ determines the 'fatness' of the distribution tail. (Smaller $\alpha$ indicates a fatter tail). Table 1 shows estimates of this power-law exponent 


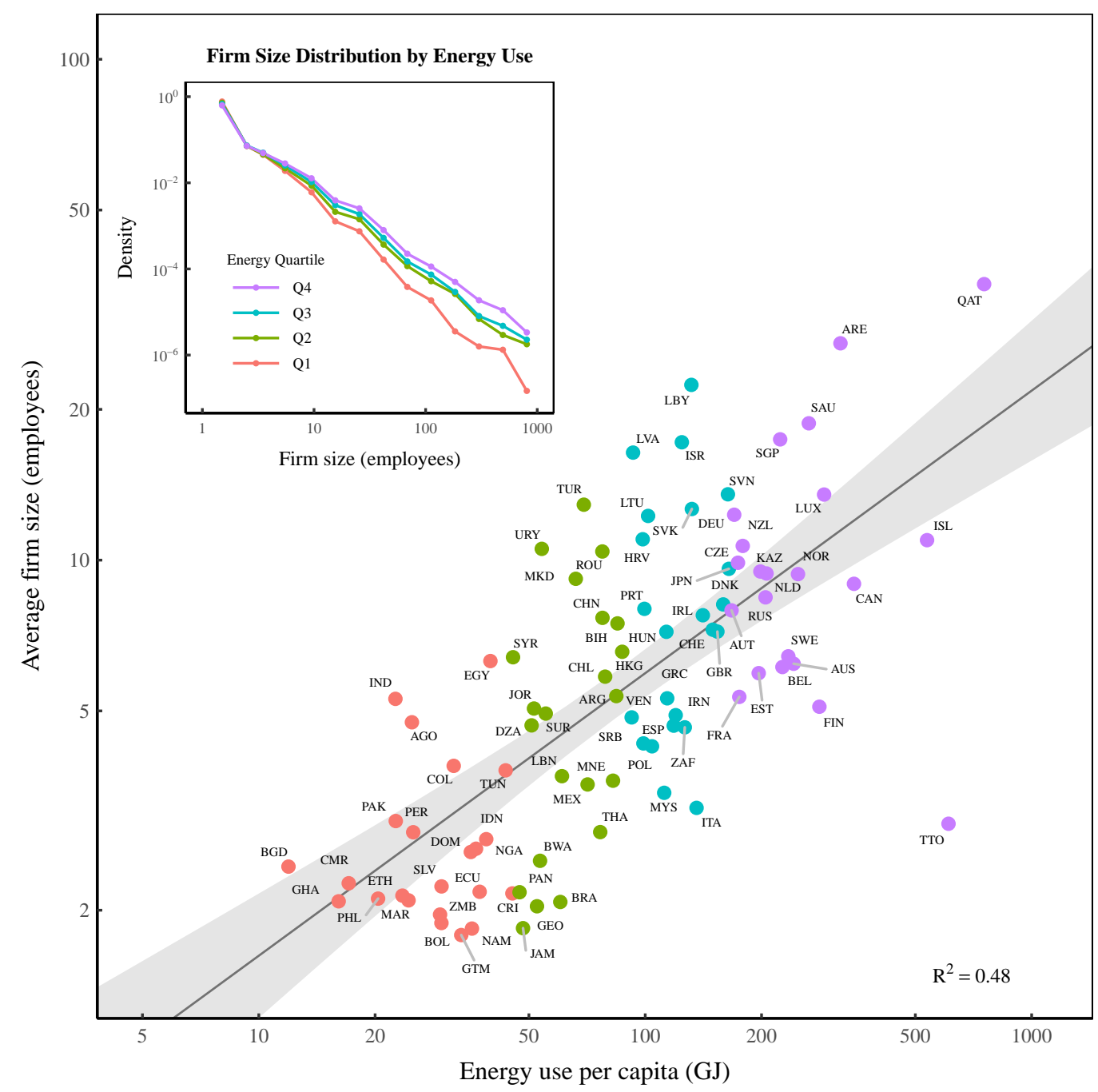

Figure 8: How firm size changes with energy use

This figure compares the average size of firms (within countries) to energy use per capita. Countries are labeled with alpha-3 codes. Color indicates the energy quartile of each country (its rank, by energy use, in a four-class quantile). The black line shows a $\log$-log regression, with the associated $95 \%$ confidence interval. The inset panel shows the associated firm-size distributions. Within each energy quartile, I plot (on a log$\log$ scale) the aggregate size distribution of firms (i.e. the size distribution across all countries in the quartile). For sources and methods, see Section 6. 
Table 1: Firm-size statistics by energy-use quartile

\begin{tabular}{cccc}
\hline Energy quartile & $\begin{array}{c}\text { Average energy } \\
\text { use per capita } \\
(\mathrm{GJ})\end{array}$ & Average firm size & $\begin{array}{c}\text { Power-law } \\
\text { exponent of firm } \\
\text { size distribution }\end{array}$ \\
\hline Q1 & 27.9 & 2.6 & 2.09 \\
Q2 & 63.8 & 4.7 & 1.94 \\
Q3 & 121.8 & 7.5 & 1.85 \\
Q4 & 257.4 & 9.5 & 1.74 \\
\hline
\end{tabular}

Notes: Statistics are for groups of countries ranked by energy-use quartile (see Fig. 8). Average energy use is calculated as the unweighted mean of per capita energy use within each energy quartile. Firm-size statistics are calculated on the aggregate firm-size distribution within each energy quartile. For sources and methods, see Section 6.

across countries of the world, grouped by energy quartile. I find that as energy use increases, $\alpha$ tends to decrease. This evidence suggests that the size distribution of institutions can be modeled as a power-law that varies with energy use.

Back to the Simon-Lydall model of hierarchy. Based on the evidence in Figure 8, I input to the Simon-Lydall model a size distribution of institutions drawn from a discrete power law. To simulate changing energy use, I allow the exponent $\alpha$ to vary between model iterations. I then model energy use per capita $\left(E_{p c}\right)$ as a function of average firm size, $\bar{N}$ :

$$
E_{p c}=a \cdot(\bar{N})^{b}
$$

To set the parameters $a$ and $b$, I regress Eq. 10 onto the firm-size data shown in Figure 8.

\section{Modeling government as the largest 'firm'}

The evidence in Figure 8 shows the size distribution of firms. But how does government fit into the picture? I propose we model government as the largest firm(s).

This idea is inspired not by the social sciences, but by a stunning biological regularity. Across the entire range of life (from bacteria to large mammals) the 
abundance of organisms declines predictably with mass (Hatton et al., 2019). Small organisms are ubiquitous. Large organisms are rare. This pattern is called the biomass spectrum (Sprules and Barth, 2016).

To model government size, I take inspiration from this regularity amidst difference. Elephants are different than bacteria, yet their abundance is still predictable from their size. Might the same be true of government?

Yes, governments are different than other institutions. Governments can tax their citizens, enforce laws and wage war - all things that firms cannot do. But what if, despite these differences, governments fit into the overall size distribution of institutions? Suppose that governments behave as if they were the largest 'firms'. If so, then we can predict the employment share of government from the size distribution of institutions.

With this thinking in mind, I model governments as the $n$ largest institutions. Formally, given a size distribution of institutions $N_{i}$, the government fraction of employment $G_{\text {frac }}$ is the sum of the top $n$ institutions expressed as a fraction of the total population:

$$
G_{\text {frac }}=\frac{\sum_{\text {top n }} N_{i}}{\sum_{\text {all }} N_{i}}
$$

Here $n$ (the number of 'firms' in government') is a free parameter.

\section{The energy-hierarchy model}

When we merge the Simon-Lydall model of hierarchy with the model of how institution size varies with energy use, we get something that I call the energyhierarchy model. This is a numerical simulation of how the hierarchical structure of society varies as energy use increases.

The energy-hierarchy model has 3 free parameters, summarized in Table 2. We start with a size distribution of institutions, generated using a discrete powerlaw distribution. (I simulate a population of 1 million institutions.) The exponent of this distribution, $\alpha$, varies randomly between iterations, thus producing societies with differing institution sizes. Given an institution size distribution, we then use the Simon-Lydall model to simulate the hierarchy within each institution. The 'shape' of each hierarchy is dictated by the span of control, $s$, which 
is constant across all institutions (but varies between model iterations). Last, we define 'government' as the $n$ largest institutions (where $n$ varies between model iterations).

\section{Energy-hierarchy model predictions}

The energy-hierarchy model produces the observables shown in Table 3. To test the model, I compare the first 3 observables to real-world data. Results are shown in Figures 9 and 10.

Let's begin with the size of government as it relates to energy use per capita (Fig. 9). The energy-hierarchy model predicts that governments should tend to grow larger as energy use (my measure of economic development) increases. There is, however, significant leeway for this trend to be pushed 'up' (to larger government) or 'down' (to smaller government). In the energy-hierarchy model, this leeway stems from the number of 'firms' in government. Adding more 'firms' to government increases the size of government at the given level of energy use.

I interpret the number of 'firms' in government as a political preference. Societies with leftist politics tend to let government do what, in right-wing societies, would be done by private firms. In the energy-hierarchy model, a leftward shift in politics corresponds to adding 'firms' to government. For instance, a healthcare 'firm' in a right-wing society becomes a healthcare branch of 'government' in a left-wing society. So moving left on the political spectrum involves adding 'firms' to government. Moving right involves taking 'firms' away from government.

Given this interpretation, the energy-hierarchy model suggests that politics strongly affect the size of government (something we already knew from Fig. 3). However, the model also suggests that there is a secular trend that has little to do with politics. Governments tend to get larger as energy use increases. In the energy-hierarchy model, this trend stems from a change in the size distribution of institutions, of which governments are a part. Governments, the model suggests, are riding a larger wave of institutional change.

The inset panel in Figure 9 shows how the best-fit model compares to the smoothed trend in real-world data. (For fitting methods, see Sec. 6.) In this model, government consists of the 87 largest institutions (out of a total of 1 
Table 2: Free parameters in the energy-hierarchy model

\begin{tabular}{lrl}
\hline Parameter & Symbol & Role \\
\hline Power-law exponent & $\alpha$ & $\begin{array}{l}\text { Determines the size } \\
\text { distribution of institutions (Eq. } \\
9)\end{array}$ \\
Span of control & $s$ & $\begin{array}{l}\text { Determines the 'shape' of each } \\
\text { hierarchy (Eqs. 5-7) }\end{array}$ \\
Number of 'firms' in government & $n$ & $\begin{array}{l}\text { Affects government share of } \\
\text { employment (Eq. 11) }\end{array}$ \\
\hline
\end{tabular}

Table 3: Observables predicted by the energy-hierarchy model

\begin{tabular}{ll}
\hline Observable & Description/method \\
\hline Energy use per capita & $\begin{array}{l}\text { Modeled as a function of mean institution } \\
\text { size (Eq. 10) } \\
\text { Employment share of hierarchical ranks } 3 \\
\text { and greater (Eq. 8) }\end{array}$ \\
Eovernment share of employment & $\begin{array}{l}\text { Employment share of top } n \text { institutions } \\
\text { (Eq. 11) }\end{array}$ \\
Concentration of hierarchical power (CHP) & $\begin{array}{l}\text { A measure of the degree of hierarchy - } \\
\text { the Gini index of the hierarchical-power } \\
\text { distribution (Eqs. 1-2) }\end{array}$ \\
Global reaching centrality (GRC) & $\begin{array}{l}\text { A measure of the degree of hierarchy } \\
\text { (Eqs. 3-4) }\end{array}$ \\
\hline
\end{tabular}




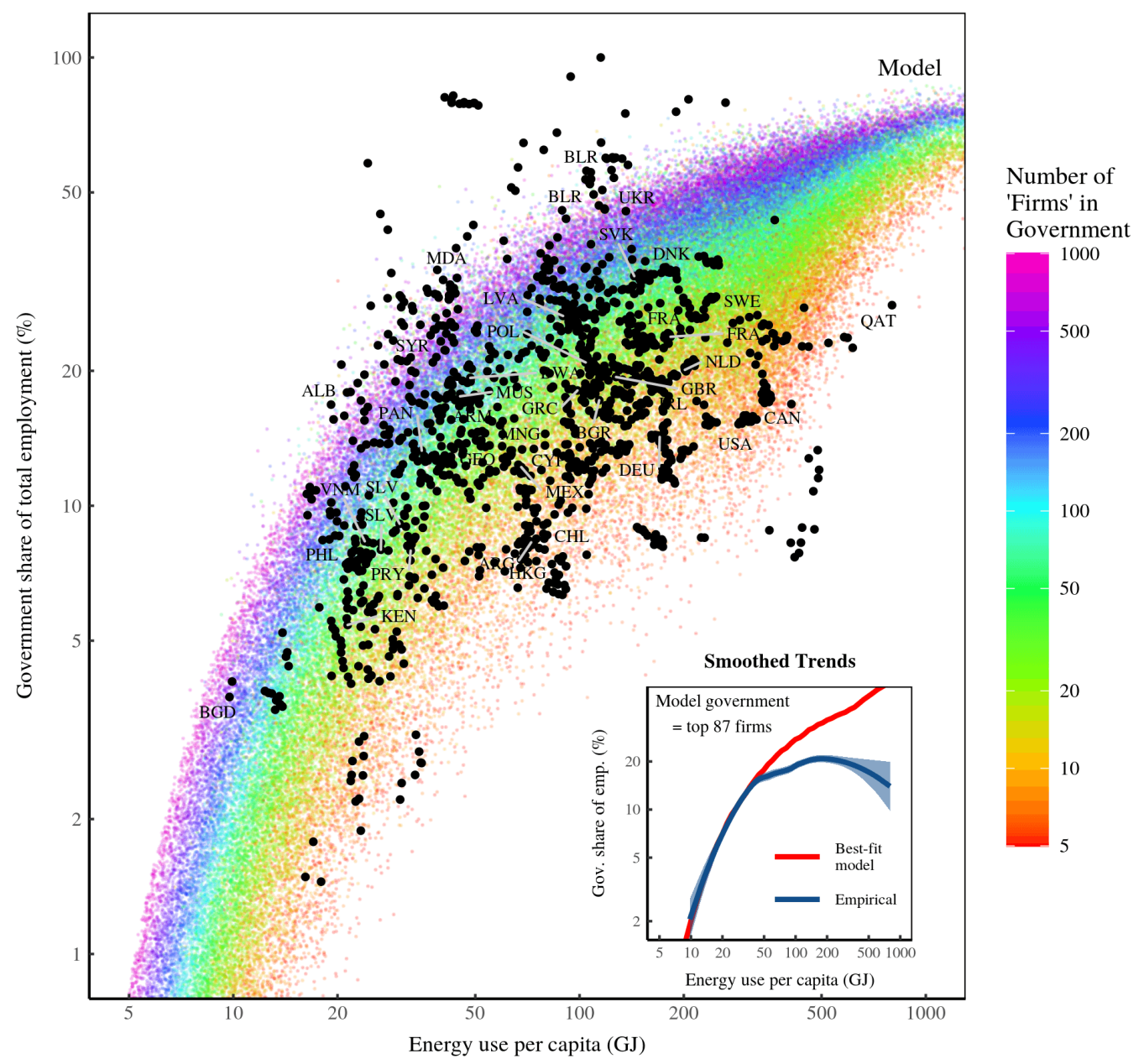

Figure 9: The modeled growth of government with energy use

This figure compares empirical and modeled trends between the government share of employment and energy use per person. Each colored dot represents an iteration of the energy-hierarchy model. Color indicates the number of 'firms' in modeled government (the model's sole parameter). Black points represent real-world data, with select countries labeled with alpha- 3 codes. The inset panel shows the smoothed trends for the empirical data and the best-fit model. For sources and methods, see Section 6 . 


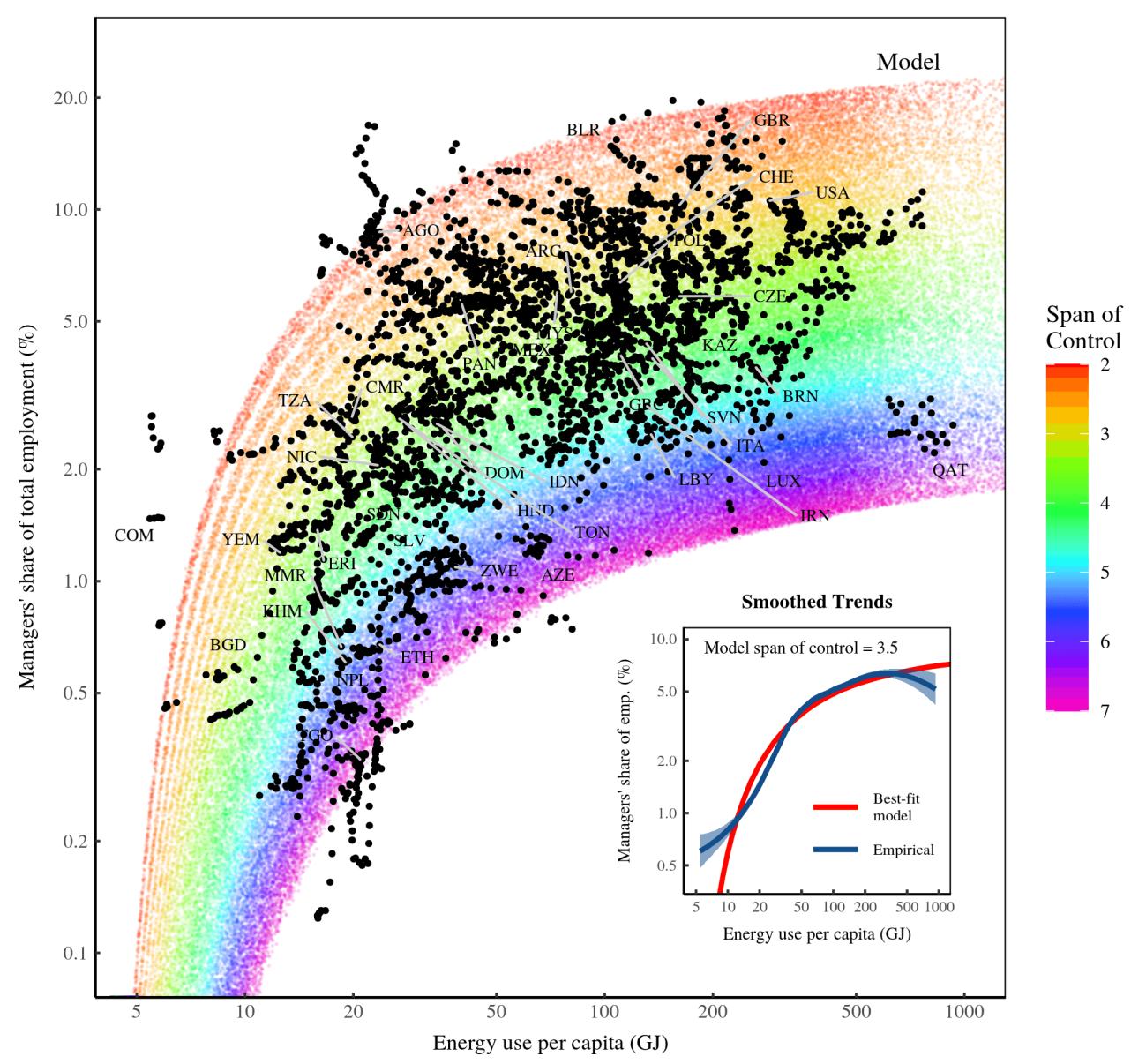

Figure 10: The modeled growth of management with energy use

This figure compares empirical and modeled trends between the management share of employment and energy use per person. Each colored point represents an iteration of the energy-hierarchy model, with color indicating the span of control. Black points represent real-world data, with select countries labeled with alpha-3 codes. The inset panel shows the smoothed trends for the empirical data and the best-fit model. For sources and methods, see Section 6. 
million). The best-fit model closely predicts the growth of government during initial stages of development. For large energy use, however, the model diverges from the real-world trend. This may be because the model is wrong. Or it could be that political preferences (for government) change with energy use. I leave it for future research to better understand this discrepancy.

Let's switch now to how the relative number of managers varies with energy use (Fig. 10). The energy-hierarchy model predicts that as societies use more energy, they should accumulate managers. The trend, however, is non-linear. In the limit of high energy use, the managers' share of employment plateaus. This is a characteristic feature of the energy-hierarchy model. As societies accumulate hierarchy, the relative number of managers approaches an asymptote of $1 / s^{2}$ (where $s$ is the span of control). This limit corresponds to a society organized in a single hierarchy.

In the energy-hierarchy model, the managers' share of employment is affected by the span of control. A smaller span of control produces 'steeper' hierarchies with more managers. A larger span of control produces 'flatter' hierarchies with fewer managers. Since the span is a free parameter, it is important to verify that fitted values are consistent with empirical data. In Figure 10, virtually all of the empirical data can be fitted with a span of control between $2 \leq s \leq 7$. I show in Fig. 14 (Sec. 6) that this range is consistent with the existing studies of firm hierarchy.

The inset panel in Figure 10 compares the best-fit model (which has a span of control of $s=3.5$ ) to the smoothed trend in real-world data. (For fitting methods, see Sec. 6.) The fit is quite close, departing only at extremes of energy use, where the empirical sample size is small.

To summarize, the energy-hierarchy model predicts (with reasonable accuracy) the growth of government and managers' employment with energy use.

\subsection{Inferring how the degree of hierarchy varies with energy use}

Having validated the energy-hierarchy model, I now use it to infer how the 'degree of hierarchy' varies with energy use.

The inference procedure is as follows. For each empirical observation (a country in a given year), I find the model iteration that best reproduces the 
observed level of energy use and managers' share of employment. (For fitting methods, see Sec. 6.) I then take this model iteration, and input its simulated data into the two metrics of hierarchy - the CHP and the GRC (Sec. 3.2). The result is an inferred relation between energy use and the 'degree of hierarchy' within each country.

The model-based inferences are shown in Figure 11. Here I plot the inferred trend between energy use per capita and the 'degree of hierarchy' within each country. The main panel measures hierarchy using the concentration of hierarchical power (CHP), while the inset panel uses global reaching centrality (GRC). Both metrics indicate that the degree of hierarchy tends to increase with energy use.

Because this is a model-based inference, we should treat it with appropriate uncertainty. Still, the results are provocative and not at all what neoclassical economics predicts. If these estimates are correct, they suggest that societies develop by replacing small-scale competition with large-scale hierarchy. In other words, economic development involves the gradual death of the free market.

\section{Discussion: Rethinking free-market theory}

To interpret the inferred growth of hierarchy with economic development, let's return to the competing perspectives of multilevel selection theory and the neoclassical theory of free markets. Which theory is consistent with the evidence?

I will start with multilevel selection theory, which argues that successful groups must suppress the self-interest of individuals. The theory does not stipulate how this suppression occurs, but evidence from evolutionary biology suggests that hierarchy is a common solution. The idea is that the control structure of hierarchy suppresses the fitness-seeking behavior of subunits, thus increasing the fitness of the group. Perhaps something similar happens in human societies as they develop?

If so, we can treat economic development as a type of group selection in which larger (hierarchical) groups beat out smaller (less-hierarchical) groups. How and why this happens is an open question (Bichler and Nitzan, 2020). Still, the (inferred) fact that economic development involves the growth of hierarchy is consistent with the theory of multi-level selection. 


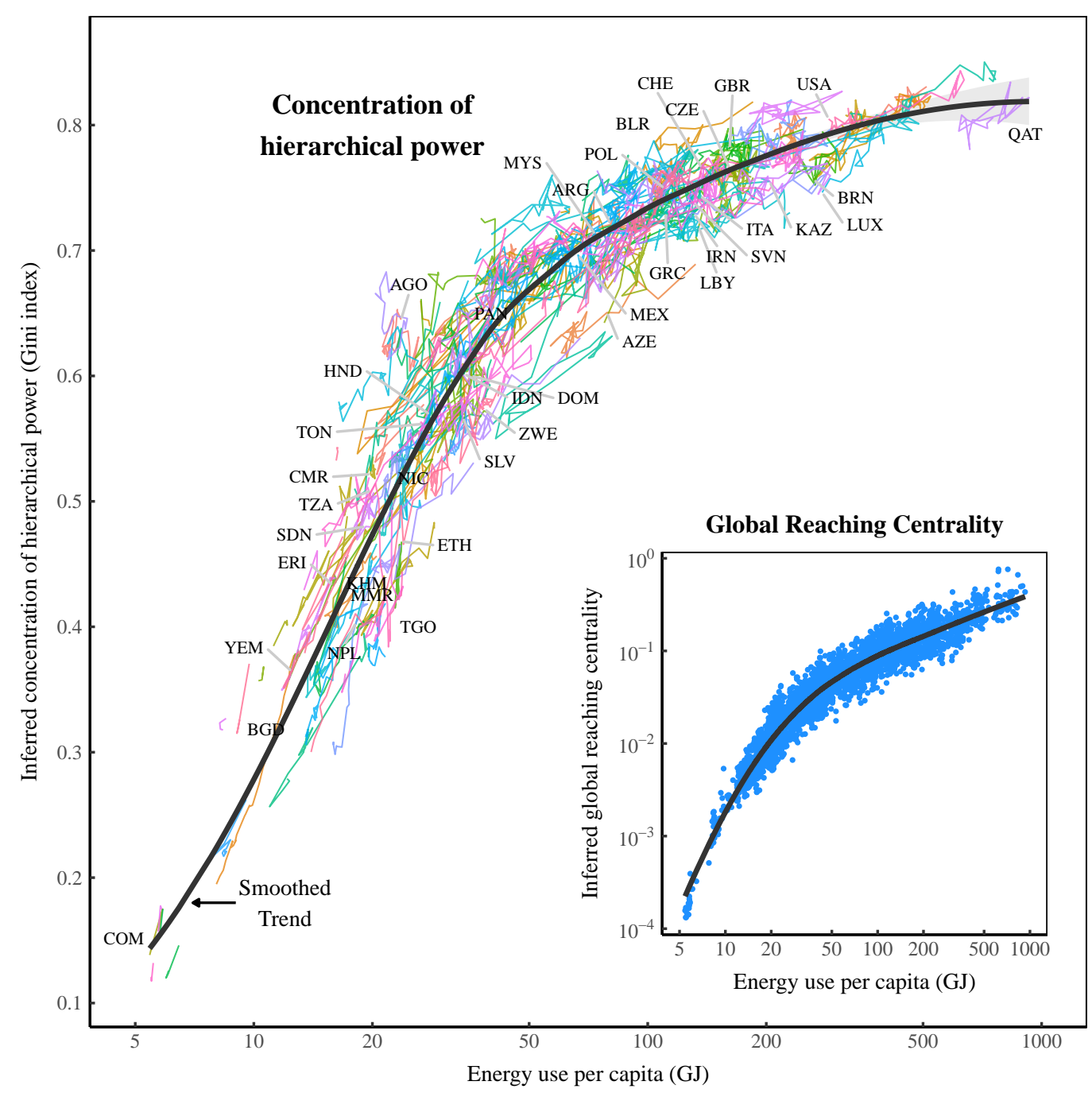

Figure 11: The inferred degree of hierarchy vs. energy use

This figure uses the energy-hierarchy model to infer how the degree of hierarchy varies with energy use per capita in real-world societies. The main panel measures hierarchy using the concentration of hierarchical power. Colored lines indicate the path through time of a country. Select countries are labeled with alpha-3 codes. The black line shows the smoothed trend, calculated with a local polynomial regression. The inset panel measures hierarchy using global reaching centrality. For sources and methods, see Section 6. 
The same evidence, however, is difficult to interpret using the neoclassical theory of free markets. According to this theory, small-scale competition is the optimal form of social organization. The idea is that by stoking self-interest, free markets maximize the welfare of society. But if this is true, why do societies turn to hierarchy to develop?

We can rescue neoclassical theory by supposing that societies would be better off if they reduced hierarchy. The problem is that this scenario requires a remarkable degree of collusion. Most developed countries seem to organize in a way that neoclassical theory says is 'non-optimal'. But why would they do that? It could be that politics 'distort' the free-market. Yet we saw in Figure 5 that political regimes have no effect on the relative number of managers. That leaves free-market theory in an uncomfortable situation. For unknown reasons, countries of the world are pursuing a path to development that neoclassical theory says is 'inefficient'.

We can always appeal to 'distortions' to rescue neoclassical theory. But this is what philosophers of science call an auxiliary hypothesis - an idea that is used solely to rescue a theory from falsification (Lakatos, 1976; Popper, 1959). Worse still, the concept of 'distortion' is almost impossible to test. What evidence would show that developed economies are not distorted? According to neoclassical theory, finding a perfectly competitive market would suffice. But that leads to tortuous logic. Either free-market theory is both true and consistent with the evidence, in which case we find perfect competition. Or free-market theory is still true but inconsistent with the evidence, in which case we infer that the economy is distorted. Either way, the theory wins.

A less tortuous alternative is to conclude that the evidence is inconsistent with neoclassical theory. Rather than develop via the free market, societies turn to hierarchy.

\subsection{The two sides of a social-science theory}

Were we studying non-human animals, we could leave the discussion at that. The evidence favors multilevel selection theory over the neoclassical theory of free markets. The problem, though, is that we are studying humans - an animal whose behavior is shaped not just by instinct, by also by beliefs. 
This entangling of beliefs and behavior means that doing social science is more complicated than doing natural science. When we evaluate a social-science theory, not only must we study its factual merit, we must also study the theory's effect on behavior. Importantly, the two components of the theory need not be consistent.

Put simply, a social-scientific theory can be factually incorrect and yet ideologically potent. Take, as an example, Karl Marx's theory of capitalism (Marx, 1867). Many critics think the theory has gaping flaws (Keen, 2001; Nitzan and Bichler, 2009; Robinson, 1962; Samuelson, 1971). And yet virtually no one disputes Marx's impact on history. Without Marx's ideas, there may have been no communist revolutions. So regardless of its scientific merit, Marx's theory had a strong influence on human behavior.

When social-science theories are obscure, of course, we need not worry about their ideological effect. But when a theory becomes popular — as in the case of Marxism - we must pay attention to its effect on behavior. In the case of Marxism, the effect was straightforward. Marx claimed that the injustices of capitalism could be solved only by communist revolution (Marx and Engels, 1967). Inspired by Marx's ideas, revolutionaries like Lenin and Mao did precisely what Marx proposed - they led communist revolutions to overthrow capitalism.

When it comes to free-market theory, however, the ideological component is less easily understood. On the face of it, free-market theory advocates atomistic competition. Yet the theory became popular (during the 20th century) at precisely the time when small-scale competition was being replaced by large-scale hierarchy.

Figure 12 shows this trend in the United States. Here I plot the relative word frequency (in American written English) of four free-market terms: 'small business', 'free market', 'competitive market' and 'perfect competition'. I take this word frequency as a measure of the prevalence of free-market ideas. Against this word frequency, I plot our two proxies for hierarchy: the government share of employment and the management share of employment. Over the last century, it seems that at the same time that hierarchy grew, free-market jargon became more common.

How should we interpret this trend? One possibility is that the spread of free-market language was a reaction to the growth of hierarchy. After witnessing 


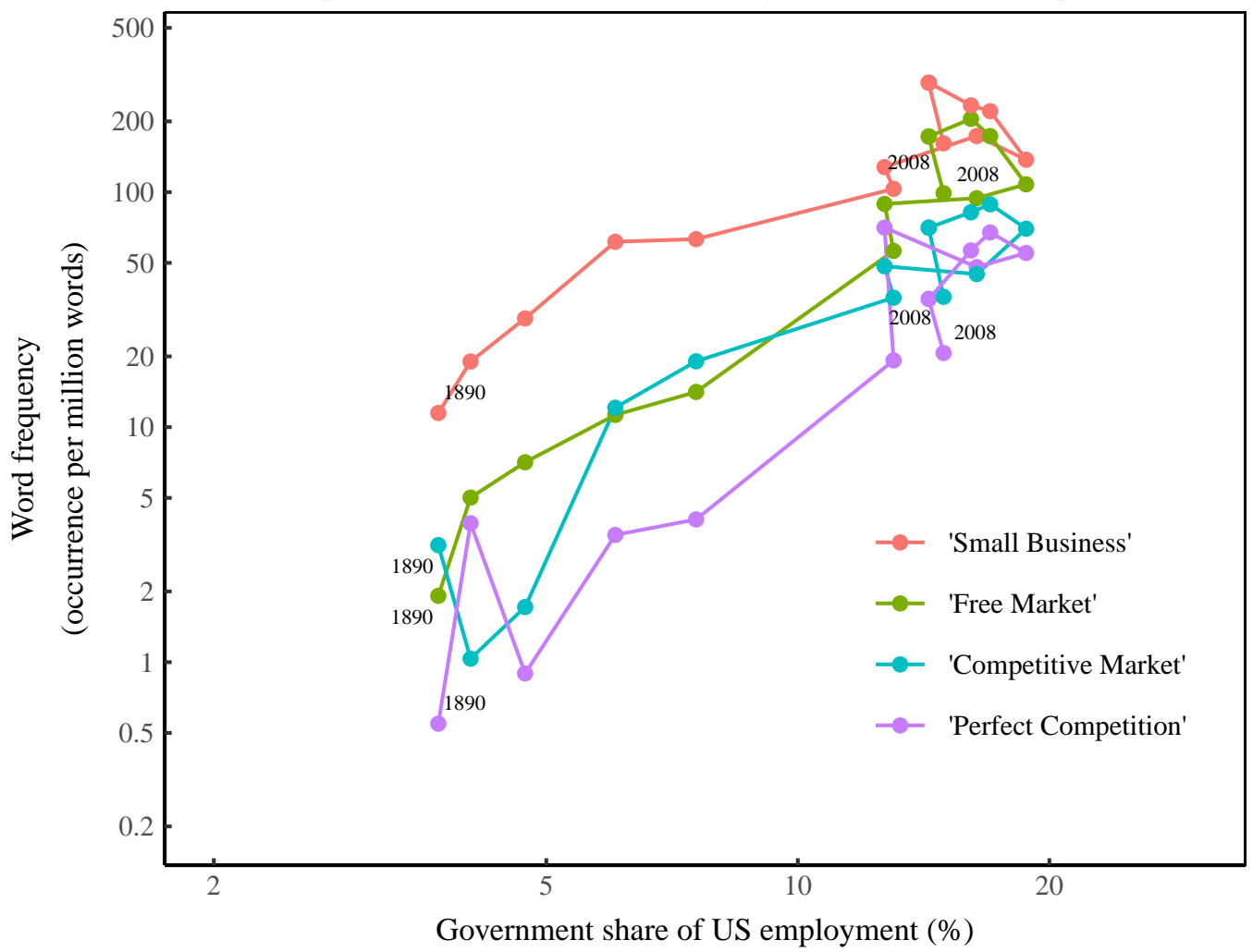

B. Frequency of free-market terminology vs. management employment

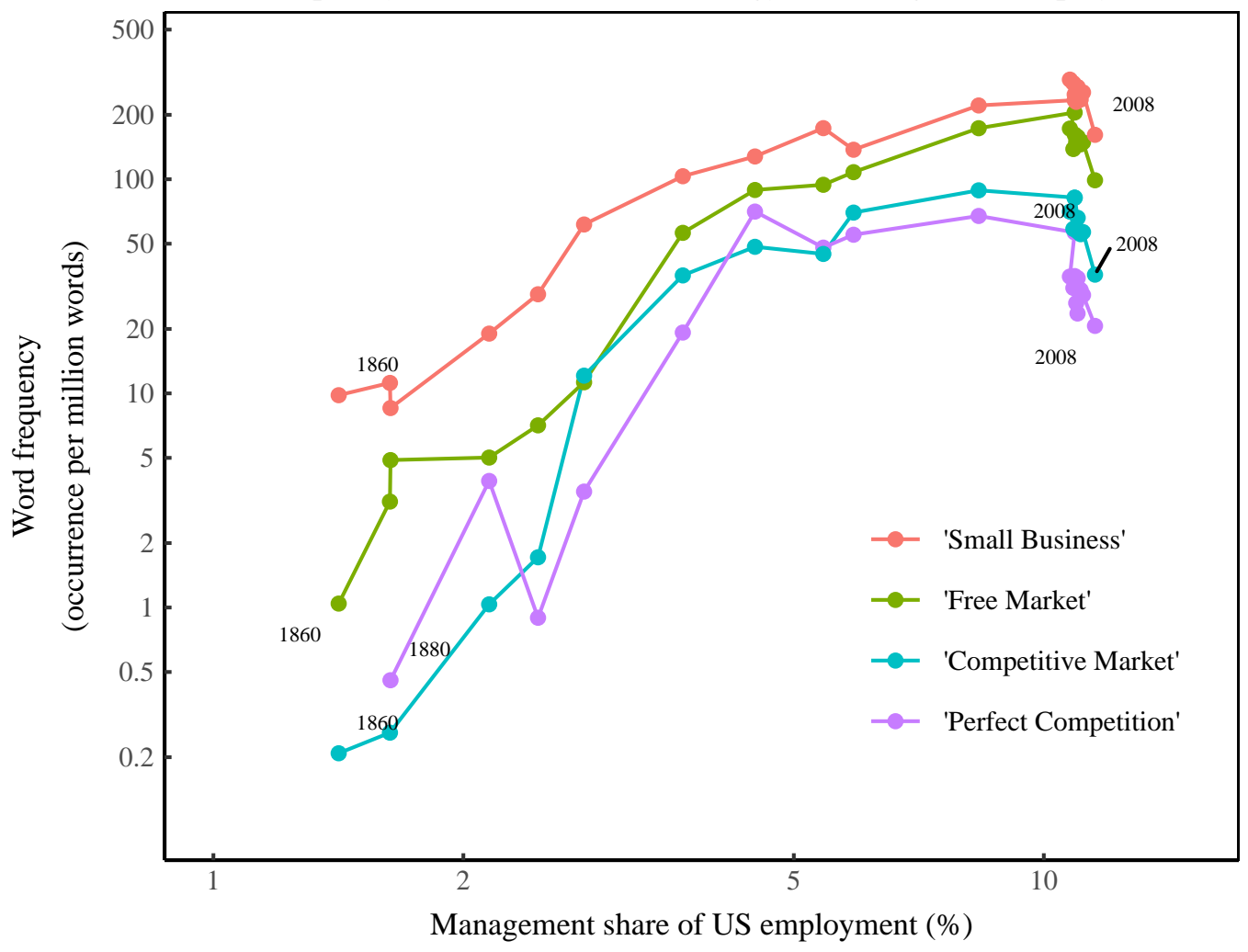

Figure 12: Frequency of free-market terminology in American English vs. trends in hierarchy

This figure shows the relative frequency in American English of four free-market terms. Panel A compares this word frequency to the government share of US employment. Panel B compares it to the management share of employment. From 1860-2000, the time interval is decadal. From 2000 onward, the time interval is annual. For sources and methods, see Section 6. 
the growth of government and large firms, free-market proponents reacted by writing more frequently about the merits of small-scale competition. But despite the increasing prevalence of their ideas, free-market thinkers were unable to stop the growth of government and large firms. If this interpretation is correct, then free-market ideas do have an atomistic effect. It is just that this thinking failed to catch hold.

There is, however, another interpretation of the evidence. When we separate a theory into a scientific and ideological component, there is no reason that the two sides must connect. In other words, the ideological effect of a theory (its effect on human behavior) can be different from the theory's factual claims. Free-market theory argues that small-scale competition is the most effective form of social organization. But when put into action, perhaps free-market ideas do the opposite of what they claim. Might free-market thinking foster the growth of hierarchy? The evidence in Figure 12 suggests that this possibility is worth exploring.

\subsection{Belief systems as 'massive fictions'}

According to multilevel selection theory, social animals face a fundamental dilemma. To be successful, social groups must suppress the selfish behavior of individuals. The problem is that within the group, selfish behavior is advantageous. David Sloan Wilson and E.O. Wilson call this dilemma the 'fundamental problem of social life' (Wilson and Wilson, 2007). The existence of sociality, they argue, is predicated on solving this problem.

Humans, it seems, have developed a way to motivate altruism that is unique. We rely, at least in part, on the power of beliefs. Successful groups adopt belief systems that motivate group cohesion (Turchin, 2016). Importantly, these beliefs need not be scientifically true. As long as they motivate pro-social actions, beliefs can be factually inaccurate - sometimes wildly so. For this reason, David Sloan Wilson argues that belief systems are often 'massively fictional':

Groups governed by belief systems that internalize social control can be much more successful than groups that must rely on external forms of social control. For all of these (and probably other) reasons, we can expect many belief systems to be massively fictional in their portrayal of the world. 
(Wilson, 2010, emphasis added)

To solve the fundamental problem of social life, Wilson argues that belief systems contain a (possibly universal) untruth. They portray altruistic behavior as beneficial to the individual. In so doing, these belief-systems promote altruism by denying the sacrifice that it necessarily (according to multilevel selection theory) involves.

As an example of such a 'massively fictional' belief system, Wilson studies the worldview of the Hutterites (a communal sect of Protestants living in northwestern North America). The Hutterite worldview, Wilson finds, contains no grey areas (Wilson, 2015). Actions are portrayed as either good for both individuals and groups, or bad for both individuals and groups. By masking the costs of altruism, this belief system may help Hutterites motivate communal behavior.

Interestingly, Wilson finds a striking parallel between the communal beliefs of the Hutterites and the libertarian (i.e. free-market) beliefs of Ayn Rand (Wilson, 2015). Like the Hutterites, Rand's worldview seems to have no grey areas. Actions are portrayed as either good for both individuals and the group, or bad for both individuals and the group. There is, however, an important distinction between the Hutterites' beliefs and Rand's libertarianism. The Hutterites portray prosocial behavior (traits like 'brotherliness' and 'mutual help') as good for both the individual and the group. Rand, in contrast, portrays antisocial behavior (traits like 'egoism' and 'selfishness') as good for both the individual and the group.

Noting this fact, Wilson argues that Rand's worldview - and free-market thinking in general - may be detrimental to group cohesion. This conclusion is reasonable. But it presumes that free-market ideas (which are avowedly antisocial) lead to antisocial behavior. It is possible, however, that the reverse might be true. Free-market ideas might actually promote prosocial behavior by motivating the formation of hierarchy.

\subsection{Does free-market thinking motivate hierarchy?}

Although we do not commonly think of them this way, hierarchical relations involve altruism. In a hierarchical relation, one person submits to the will of another. By doing so, the subordinate suppresses their own self-interest, and 
instead does what their superior commands. This is a form of altruism (Fix, 2019b). The question that concerns us here is - how do societies motivate this submissive behavior?

An obvious way is to openly promote subservience. Societies that take this route will promote submission as being beneficial to individuals. The Hutterites, for instance, seem to do just that. Their belief system promotes 'obedience' and 'surrender' as good for both individuals and the group (Wilson, 2015). Other religions similarly promote submission. Obsequium religiosum - religious submission - is a central tenet of Catholic dogma (Council, 1964). Confucianism advocates tsun-wang - submission to authority (Wood, 1995). And in Islam, 'submission' is implied in the name of the faith itself (Lewis and Churchill, 2008).

To promote hierarchy, however, this appeal to submission must have an asymmetry. To function, hierarchies require both submission and dominance. So behind the appeal to submission, there must be an assumption that not everyone submits. Some people must have the right to wield authority. In religious hierarchies, this asymmetry is often maintained by appealing to the authority of God. Everyone submits to the will of God, but not equally so. Some people those with power - claim to speak for (or derive their authority from) God. This leads to doctrines like the 'divine right of kings' (Figgis, 1922). The pharaohs of ancient Egypt went so far as to proclaim themselves gods (Collins, 2014).

Using the language of Michele Gelfand (2019), we might call the appeal to submission the 'tight' approach to motivating hierarchy. It openly asks individuals to submit to authority. Is there a corresponding 'loose' approach to motivating hierarchy? I propose that free-market thinking - with its emphasis on choice and freedom (Friedman, 1962; Friedman and Friedman, 1990) — may be one such 'loose' approach.

This claim appears, at first, to be contradictory. So-called 'loose' cultures value freedom and autonomy, which are the opposite of hierarchy. It is possible, however, for the idea of freedom to lead to its mirror opposite. The reason has to do with the concept of 'freedom' itself.

In an important sense, 'freedom' is impossible among social animals. The problem is that there are two types of freedom that, when applied to all individuals, are contradictory. First, there is 'freedom to', which is about one's ability to enact one's will. Second, there is 'freedom from', which is about one's ability 
to avoid the undesirable actions of others. The two types of freedom contradict one another. Everyone cannot, for instance, be free to be racist while also being free from racism. One person's 'freedom to' comes at the cost of another person's 'freedom from'.

Much like proclaiming that everyone should be submissive, advocating for 'market freedom' for all individuals is a contradiction. This, I believe, may be how free-market thinking motivates hierarchy. When applied to the real world, the 'freedom' of the free market is marked by an asymmetry. In abstract form, free-market theory stands for the autonomy of individuals. But in more concrete form, the theory stands for the autonomy of firms. This switch is apparent in neoclassical economic theory. The theory proposes that 'perfect competition' (implying atomistic competition between individuals) is the ideal form of social organization. But the same theory accepts that firms (which organize using hierarchy) are the basic unit of production (Mankiw, 2012).

This switch from the autonomy of the individual to the autonomy of the group, I propose, is how free-market ideas promote hierarchy. It is easiest to see how this might work by applying the idea to ourselves. We use the word 'free will' to describe our own freedom to put conscious thoughts into action. Yet when we look inside ourselves, the concept of 'free will' is contradictory. Individual humans are a community of cooperating cells, organized in a hierarchy. This means that our 'free will' is predicated on a large number of cells being 'unfree'. If you are free to lift your arm at will, this requires that brain cells have control over muscle cells. So the 'free will' of the individual is predicated on the 'unfreedom' of most of the individual's constituents.

I propose that the same principle applies when free-market ideas are put in action. While, in principle, they stand for the autonomy of the individual, in practice they stand for the autonomy of business firms. By promoting this autonomy, these ideas may implicitly legitimize the hierarchy within firms. The 'freedom' of the free market therefore translates into the power of firm owners to command. It is 'power in the name of freedom'8. This doublespeak may be why free-market thinking has spread at the very time that hierarchy appears to have increased. Contrary to the theory's scientific claim, the ideological effect of free-market thinking may be to facilitate the growth of hierarchy.

This idea is speculative, but consistent with the available evidence on cultural

\footnotetext{
${ }^{8}$ I thank Jonathan Nitzan for suggesting to me the phrase 'power in the name of freedom'.
} 
A. Cultural individualism vs. management employment

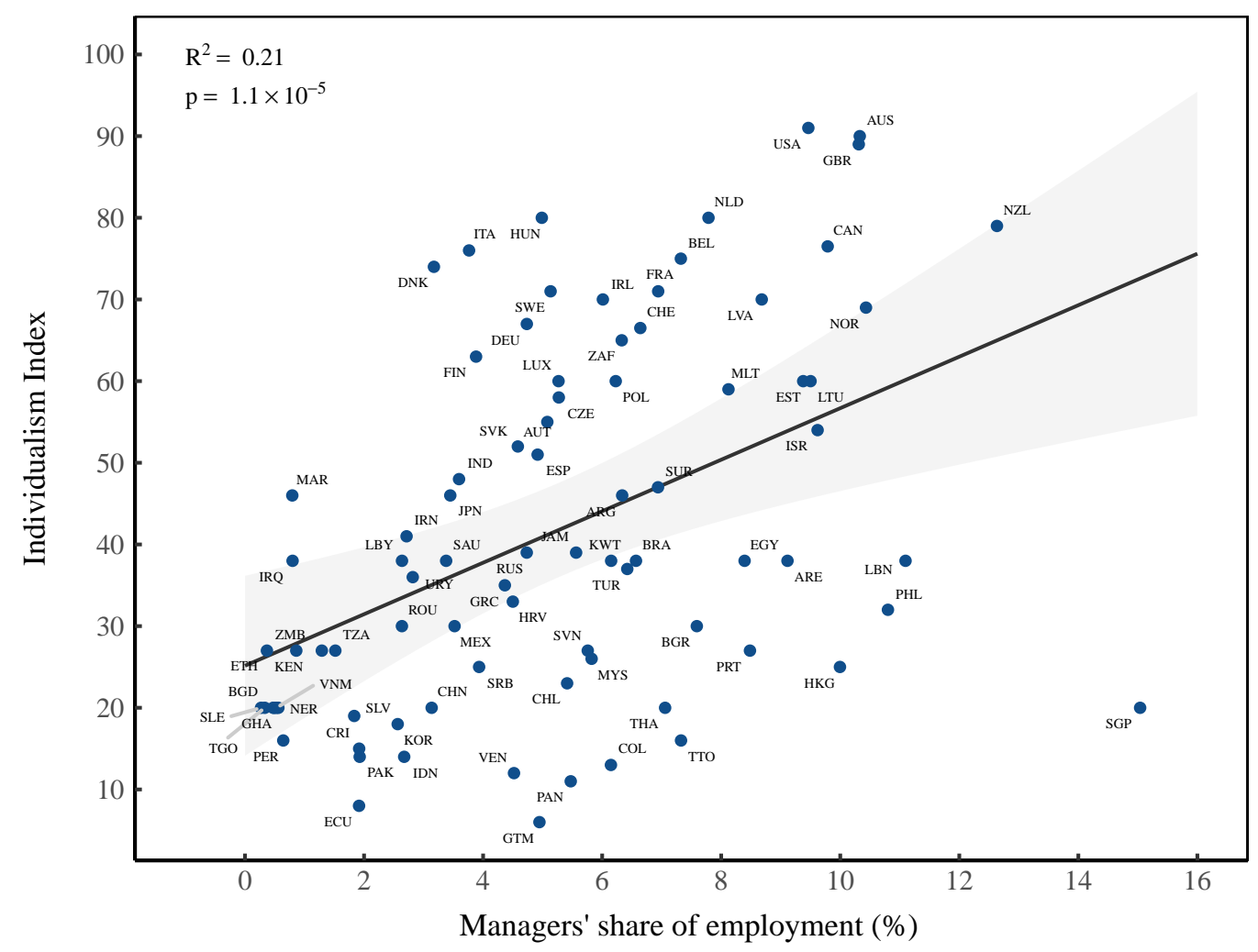

B. Cultural tightness vs. management employment

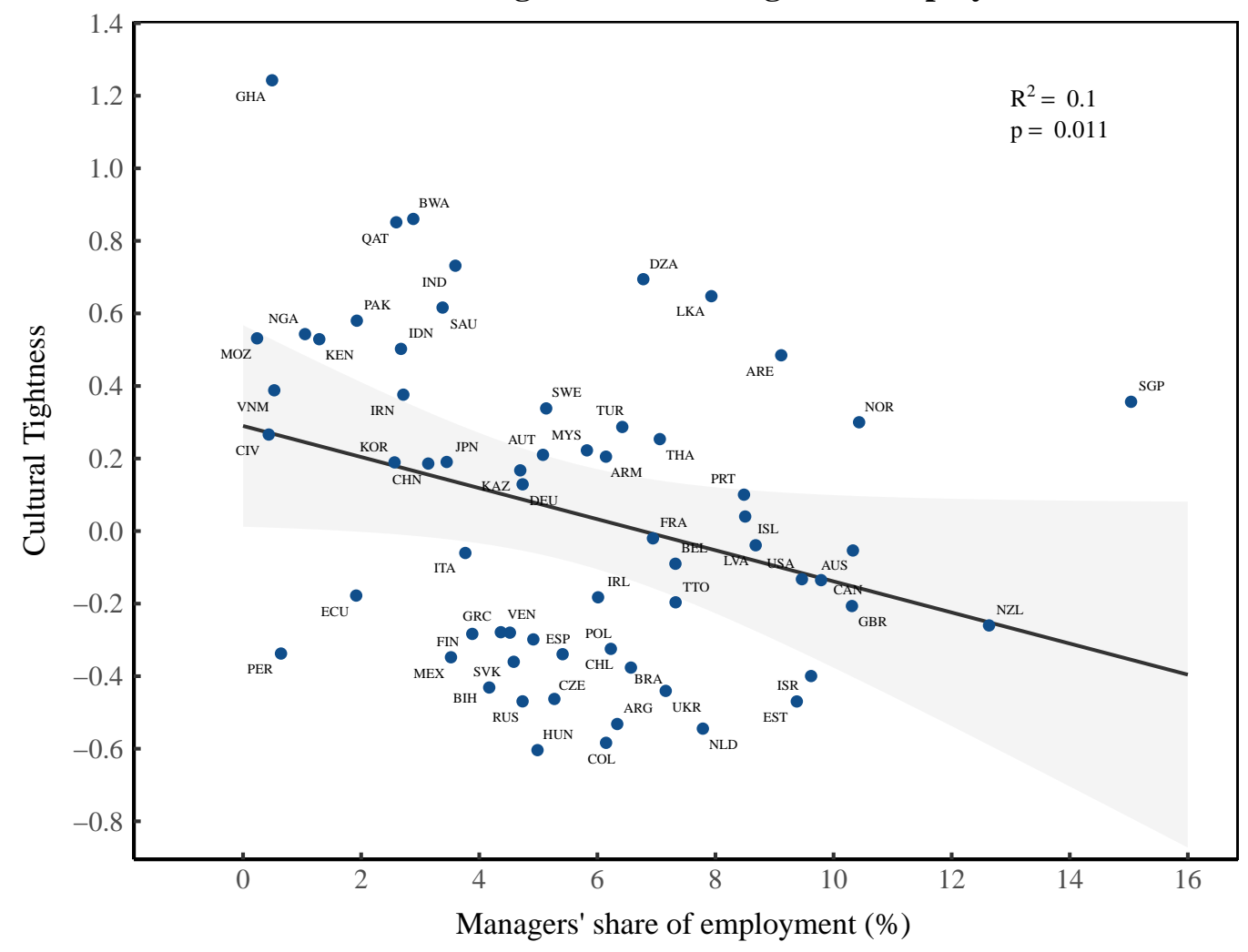

Figure 13: Cultures become more individualistic and looser as the number of managers grows

I plot here measures of cultural beliefs (within countries) as they relate to the managers' share of employment. Panel A shows Geert Hofstede's (2010) 'individualism index' - a measure of individualistic psychology. Panel B shows Michele Gelfand's (2004) index of cultural 'tightness', where 'tighter' cultures have stronger norms and a lower tolerance of deviant behavior. For sources and methods, see Section 6 . 
beliefs. On that front, Figure 13 shows a curious trend. Countries with a more individualistic psychology (as measured by Gerte Hofstede's (2010) 'individualism index') tend to have more managers. Similarly, countries with a 'looser' culture (as measured by Michele Gelfand's (2004) index) also have more managers.

This result clashes with common sense. One would think that an individualistic culture with loose norms ought to have less hierarchy. Yet the reverse seems to be true. This evidence supports the idea that free-market thinking may paradoxically serve to stoke the growth of hierarchy.

\section{Conclusions}

Peter Brown and Peter Timmerman argue that mainstream economics is an 'orphaned discipline'. It is founded, they claim, on a "dated and unrevised metaphysical and prescientific vision" that is "incompatible with what we know about the universe and our place in it" (Brown and Timmerman, 2015). Looking at free-market theory in the context of the modern understanding of evolution, this assessment rings true.

Adam Smith's concept of the invisible hand was a plausible hypothesis when it was proposed more than two centuries ago (Smith, 1776). Given the state of knowledge at the time, it seemed possible that self-interest, if properly channeled, could benefit groups. But as our knowledge of evolution has progressed, this hypothesis has grown steadily less plausible. The problem is that the major transitions in evolution show a pattern that is the opposite of the invisible hand. Rather than organize decentrally, each wave of group formation seems to use at least some form of centralization. And rather than stoke the self-interest of subcomponents, successful groups seem to suppress it. And they often do so by using hierarchy.

Whether it is the symbiosis of the eukaryotic cell, the coordination in multicellular organisms, or the cooperation among eusocial animals, this pattern seems to hold. Competition among subcomponents is suppressed using some form of centralized organization. And yet, if the economic theory of free markets is correct, humans are the exception to the rule. We can organize, the theory claims, not by suppressing competition within groups, but by stoking it. 
This claim becomes even more important if we consider that modern humans may be the most recent major evolutionary transition. In the last 10,000 years we have transitioned from being a social species that lived in groups of several hundred (Dunbar, 1993, 2013; Hayden, 2001), to an 'ultrasocial' species living in groups a million strong (Gowdy and Krall, 2013, 2014; Richerson and Boyd, 1998; Turchin, 2013). If we have accomplished this feat through decentralized competition (as free-market theory claims is possible), then the evidence should surround us. And since this transition has accelerated in the last half century (McNeill and Engelke, 2016; Steffen et al., 2015), we need not look to the deep past to study it. We can look at modern trends between nations.

Looking at these trends, the evidence suggests that human societies have developed in a way that is consistent with the major evolutionary transitions of the past. As societies industrialize (by using more energy), it seems they turn not to decentralized competition, but to increasingly large-scale hierarchy.

Where, then, does this leave the neoclassical theory of free markets? A conservative conclusion is that the theory is inconsistent with the evidence. A more radical conclusion is that free-market theory is best treated not as a scientific theory, but as a belief system - a claim that heterodox political economists have made many times (Arnsperger and Varoufakis, 2006; Backhouse, 2010; Heilbroner, 1990; Hodgson, 2019; Hoover, 2003; Hunt, 2016; Martin, 1990; Nitzan and Bichler, 2009; Samuels, 1992; Söderbaum, 2008).

If this more radical interpretation is true, then we must grapple with a paradox. Free-market theory advocates the autonomy of individuals. Yet the spread of free-market thinking has happened at the very time that hierarchy seems to have increased. A plausible explanation is that when implemented, free-market ideas actually promote the growth of hierarchy. This could be because the belief in free markets contains an inherent contradiction. It advocates for the autonomy of individuals, yet it assumes that production is done by autonomous firms. The result has been that the autonomy of the firm suppresses, to some degree, the autonomy of the individual. This idea is speculative, but worth investigating further.

Given the evidence discussed in this paper, it may be time for evolutionaryminded scientists to stop treating neoclassical economics as a competing framework, and instead view it as a cultural artifact to be explained by evolutionary theory. 


\section{Sources and methods}

All data and code for this paper are available at the Open Science Framework: https://osf.io/gbvnh/. Code for the hierarchy model is available at github: https://github.com/blairfix/energy_hierarchy_mod. R versions of the hierarchy-model functions are available at https://github.com/blairfix/hmod.

\subsection{Data sources}

Communist/non-communist status. I classify a country as 'communist' if it has, or once had, a regime that claimed to be Marxist-Leninist. See the supplementary materials for a detailed list of sources.

Cultural tightness Data for cultural 'tightness' comes from Gelfand et al. (2020) and can be downloaded from the Open Science Framework: https: //osf.io/pc4ef/

Gelfand's data was first reported in a 2010 paper. I assume that this was the date of data gathering. I match Gelfand's data (in Fig. 13) with the average of the managers' share of employment (within each country) over the period 1990-2010.

Energy use per capita. Data for energy use per capita comes from the World Bank, series EG.USE.PCAP.KG.OE. To these values I add an estimate for energy consumed through food (2000 kcal per day).

Firm size. Data for firm size comes from the Global Entrepreneurship Monitor (GEM), series 'omnowjob'. To calculate firm size, I merge all data over the years 2001-2014. Because the GEM data over-represents large firms, I use only firms with 1000 or fewer employees. For method details, see the Appendix in (Fix, 2017). Power-law exponents for firm-size distributions are estimated using the R PoweRlaw package (Gillespie, 2014).

Free-market word frequency. Word frequency of free-market jargon is from the Google Ngram corpus for American English. 
Government employment. Data for government employment comes from ILOSTAT series GOV_LVL_PSE (all public sector employees). I divide this series by the size of the labor force reported in World Bank series SL.TLFTOTL.IN. Data for US government employment share (Fig. 12A) comes from:

- 1890 to 1928: Historical Statistics of the United States, Table Ba 470-477

- 1929 to present: Bureau of Economic Analysis series 6.8A-D (total persons engaged in production)

Individualism Index. Data for the 'individualism index' comes from Hofstede et al. (2010). In addition to measures for specific countries, Hofstede reports measures for the following regions: (1) Arab countries; (2) East Africa; and (3) West Africa. Based on Hofstede's notes, I disaggregate these regions as follows:

- Arab countries = Egypt, Iraq, Kuwait, Lebanon, Libya, Saudi Arabia, United Arab Emirates

- East Africa = Ethiopia, Kenya, Tanzania, Zambia

- West Africa $=$ Ghana, Niger, Sierra Leone, Togo

I assign each country Hofstede's metric for the region.

According to Hofstede, most of his data was gathered in the late 1960s and early 1970s (the dataset does not specify years). However, data for the management share of employment does not begin until 1990. To match Hofstede's data with the management data (Fig. 13), I average the latter (within each country) over the period 1990-2010.

Managers' employment. International data for the management share of employment is from ILOSTAT Table TEM_OCU, series EMPoc1P. Data for the United States (Fig. 12B) comes from:

- 1860 to 1990: Historical Statistics of the United States, Table Ba 10331046 
- 1990 to present: Bureau of Labor Statistics Current Population Survey series LNU02032453 (management employment) divided by Bureau of Economic Analysis series 6.8D (total persons engaged in production)

\subsection{Hierarchy-model equations}

The hierarchy model used in this paper is based on equations derived independently by Herbert Simon (1957) and Harold Lydall (1959). In this model, hierarchies have a constant span of control. We assume that there is one person in the top rank. The total membership in the hierarchy is then given by the following geometric series:

$$
N_{T}=1+s+s^{2}+\ldots+s^{n-1}
$$

Here $n$ is the number of ranks, $s$ is the span of control, and $N_{T}$ is the total membership. Summing this geometric series gives:

$$
N_{T}=\frac{1-s^{n}}{1-s}
$$

In my model of hierarchy, the input is the hierarchy size $N_{T}$ and the span of control $s$. To model the hierarchy, we must first estimate the number of hierarchical ranks $n$. To do this, we solve Eq. 13 for $n$ :

$$
n=\left\lfloor\frac{\log \left[1+N_{T}(s-1)\right]}{\log (s)}\right\rfloor
$$

Here \lfloor\rfloor denotes rounding down to the nearest integer.

Next we need to calculate $N_{1}$ - the employment in the bottom hierarchical rank. To do this, we rewrite Eq. 12, this time building the hierarchy from the bottom up. Starting with the bottom rank $N_{1}$, membership in each consecutive rank declines by a factor of $1 / s$. That means the hierarchy's total membership $\left(N_{T}\right)$ is given by the following geometric series:

$$
N_{T}=N_{1}\left(1+\frac{1}{s}+\frac{1}{s^{2}}+\ldots+\frac{1}{s^{n-1}}\right)
$$


Summing this series gives:

$$
N_{T}=N_{1}\left(\frac{1-1 / s^{n}}{1-1 / s}\right)
$$

Solving for $N_{1}$ gives:

$$
N_{1}=N_{T}\left(\frac{1-1 / s}{1-1 / s^{n}}\right)
$$

Given $N_{1}$, membership in each hierarchical rank $h$ is:

$$
N_{h}=\left\lfloor\frac{N_{1}}{s^{h-1}}\right\rfloor
$$

Sometimes rounding errors cause total employment of the modeled hierarchy to depart slightly from the size of the original inputted institutions. When this happens I add/subtract members from the bottom rank to correct the error. The model is implemented numerically in $\mathrm{C}++$, using the Armadillo linear algebra library (Sanderson and Curtin, 2016).

\subsection{Modeling Managers}

I model managers as all individuals in and above rank 3. In a firm with $n$ hierarchical levels, the number of managers is equivalent to the membership in a hierarchy with $n-2$ levels. Using Eq. 13, we find that the number of managers $M$ is:

$$
M=\frac{1-s^{n-2}}{1-s}
$$

By dividing Eq. 19 by Eq. 13, we can find the management share of employment $\left(M / N_{T}\right)$ in the firm:

$$
\frac{M}{N_{T}}=\frac{1-s^{n-2}}{1-s^{n}}
$$




\subsection{Finding the best-fit energy-hierarchy model}

To find the model parameters that best fit the trends in empirical data (inset Fig. 9 and Fig. 10), I first group the model results in log-spaced bins by energy use. (This smooths the stochastic noise that is built into the model.) In each bin, I calculate the average energy use and the average of the statistic of interest (either the management share of employment or the government share of employment). I then interpolate linearly between these averaged points, creating a function that relates energy use to the government/management share of employment. I use this numerical function to compute the error between the model and the raw empirical data. The error function is:

$$
\epsilon=\left(\log S_{r}-\log S_{m}\right)^{2}
$$

Here $S_{r}$ is the real-world statistic (either government or management share of employment) and $S_{m}$ is the model statistic. The best-fit model minimizes this error.

\subsection{Fitting the energy-hierarchy model to individual countries}

To infer the degree of hierarchy within countries (Fig. 11), I first fit the energyhierarchy model to data for individual countries. For each country-year observation, I chose the model iteration that minimizes the following error function:

$$
\epsilon=\left(\log E_{r}-\log E_{m}\right)^{2}+\left(\log M_{r}-\log M_{m}\right)^{2}
$$

Here $E_{r}$ and $E_{m}$ are energy use per capita in the real-world country and the model, respectively. $M_{r}$ and $M_{m}$ are the management share of employment in the real-world country and model, respectively. Because the energy-hierarchy model is stochastic, I choose the 10 best-fit iterations, and average the measured degree of hierarchy across these models. I then infer that the degree of hierarchy found in the real-world country is the same as found in the model. 


\subsection{Calculating the degree of hierarchy in the energy-hierarchy model}

To calculate the degree of hierarchy in the energy-hierarchy model, I assume that power relations exist only within institutions. In other words, there are no power relations between institutions.

It is worth noting that this assumption is not realistic. Studies of corporate ownership suggest that between firms, there is an interlocking network of power (Fichtner et al., 2017; Glattfelder and Battiston, 2009; Vitali et al., 2011). I ignore this complexity here for two reasons. First, it is beyond the scope of the energy-hierarchy model to simulate the network of power between firms. Second, this network is ignored by the neoclassical theory of free markets. In the neoclassical model, firms interact only by buying and selling, so there are no power relations between them.

In my energy-hierarchy model, then, I give neoclassical theory the benefit of the doubt. I assume that power-relations exist only within firms, not between them. Were we to add power relations between firms, the inferred degree of hierarchy would increase.

One more caveat. The energy-hierarchy model does not directly simulate the chain of command within hierarchies. Instead, it simulates aggregate hierarchical structure - the number of people in each rank. To calculate the number of subordinates controlled by an individual, I assign each modeled person the average number of subordinates below their rank, defined as:

$$
\bar{N}_{s}(h)=\frac{\sum_{1}^{h-1} N_{i}}{N_{h}}
$$

Here $h$ is the hierarchical rank, $N$ is the membership in each rank, and $\bar{N}_{s}$ is the average number of subordinates. I then input the distribution of $\bar{N}_{s}$ into the formulas for the concentration of hierarchical power (Eqs. 1-2) and global reaching centrality (Eqs. 3-4). 


\subsection{Differences between CHP and GRC}

My two metrics of hierarchy - the concentration of hierarchical power (CHP) and global reaching centrality (GRC) - both agree that the 'least hierarchical' network is one in which nobody has subordinates. But the two metrics disagree about what type of network is the 'most hierarchical'.

The GRC assumes that the most hierarchical network is one in which all people are directly under the command of a single person. This is a society consisting of a single hierarchical firm, in which the CEO directly commands everyone else.

Whether such a society is indeed the 'most hierarchical' is a matter of definition. In an engineering scenario (where the GRC is derived), it makes sense to define the most hierarchical network as one in which a single node directly controls all other nodes. But in human networks, this idea makes less sense. The problem is that in practice, as humans accumulate more direct subordinates, their ability to actually command any single person diminishes. An army general may easily command 10 officers. But can the same general manage 10,000 soldiers directly? Unlikely.

As humans try to directly manage more people, their subordinates become more autonomous. We have a word for this tendency. As the span of control increases, we say that the hierarchy becomes 'flatter'. To many people, a flatter organization is 'less hierarchical'. But the GRC assumes the reverse is true. That is why my other metric - the 'concentration of hierarchical power' (CHP) - is useful. In contrast to the GRC, the CHP views a steeper organization as more hierarchical.

Because the CRC and CHP disagree about what constitutes the 'most hierarchical network', they could give conflicting results for the trend in social hierarchy. One metric might increase while the other decreases. Fortunately, I do not find such a conflict (Fig. 11). The reason the two metrics agree is because their differing definitions matter only when societies approach a single hierarchy. Since no real-world society is close to this limit, the CHP and GRC show a consistent trend. 


\subsection{Verifying the energy-hierarchy model's span of control}

In the energy-hierarchy model, the span of control is a free parameter that varies between model iterations. One way to test the model is to see if the fitted values for the span of control are consistent with observations from real-world firms.

To conduct this test, I use Eq. 22 to find the model iteration that best fits the observed relation (within countries) between energy use and the management share of employment. I then take the fitted values for the span of control and compare them to real-world studies of hierarchy within firms. Figure 14 shows the results. The model's estimates for the span of control have a range that is consistent with the real-world observations. A $t$-test $(p=0.77)$ and $k s$-test $(p=$ 0.08 ) both indicate that the two distributions are statistically indistinguishable at the $5 \%$ level.

\section{Funding}

This research was funded in part by John Medcalf, Mike Tench, Robin Shannon, Brent Gulanowski, Tom Ross, Steve Keen, Hilliard MacBeth, Joe Clarkson, Grace and Garry Fix, Pierre, Norbert Hornstein, and Ed Zimmer.

\section{Conflicts of Interest}

The author has no conflicts of interest to declare that are relevant to the content of this article. 


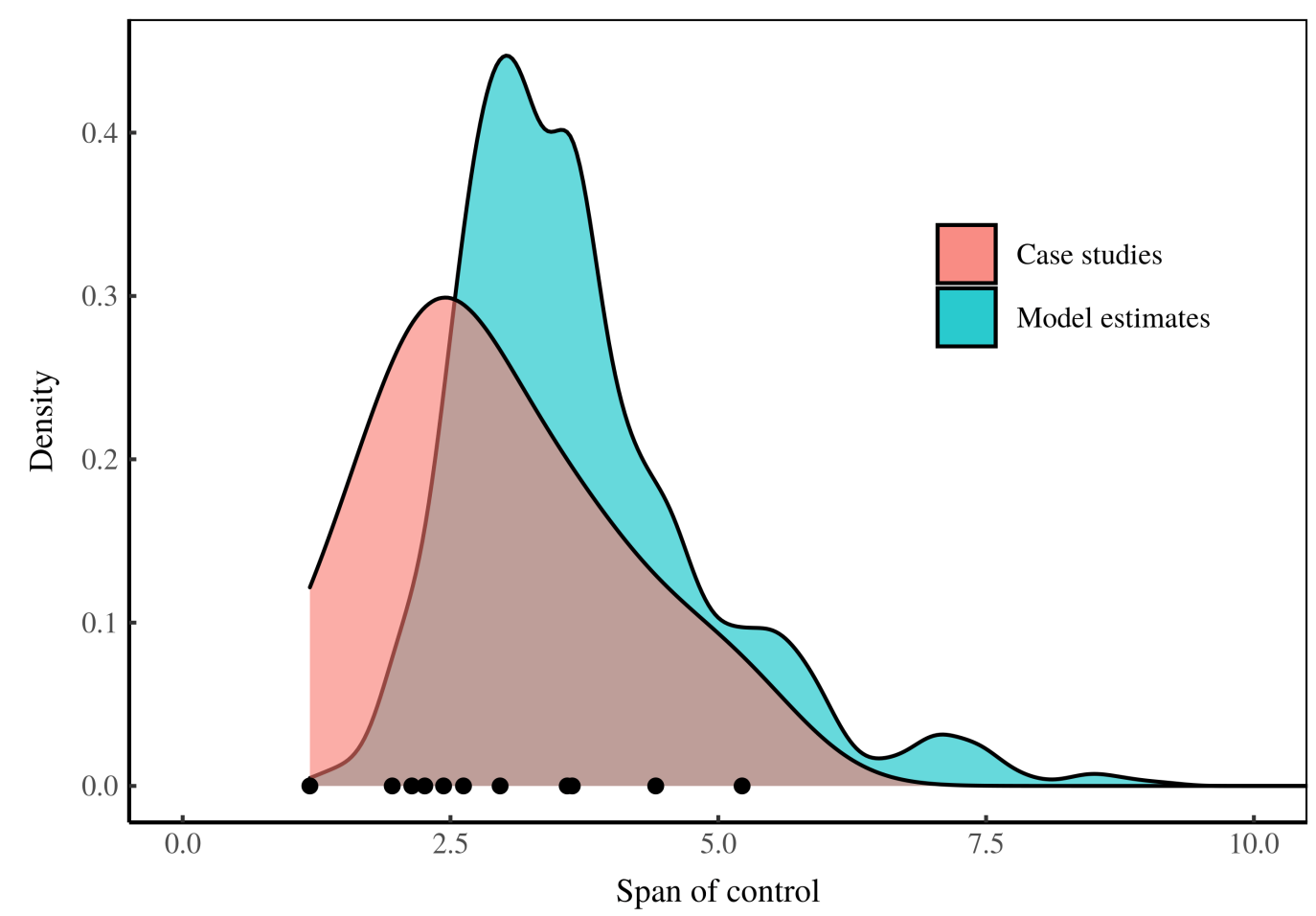

Figure 14: Span of control - empirical data and model estimates

The red distribution shows density estimates for the span of control in the available studies of firm hierarchy. Data is from Ariga et al. (1992); Audas et al. (2004); Baker et al. (1993); Bell and Van Reenen (2012); Dohmen et al. (2004); Eriksson (1999); Heyman (2005); Lima (2000); Morais and Kakabadse (2014); Mueller et al. (2016); Rajan and Wulf (2006); Treble et al. (2001). Because these studies report data over differing timeframes, I first average the spans reported by each study. I then plot the distribution of these averages. The black points on the $x$-axis show the individual averages. The blue distribution shows density estimates for the span of control fitted by the energy-hierarchy model. The two distributions are statistically identical at the $5 \%$ level. 


\section{References}

Acemoglu, D. and Robinson, J. A. (2001). Inefficient redistribution. American Political science review, pages 649-661.

Aktipis, A. (2016). Principles of cooperation across systems: from human sharing to multicellularity and cancer. Evolutionary Applications, 9(1):17-36.

Annila, A. and Annila, E. (2008). Why did life emerge? International Journal of Astrobiology, 7(3-4):293-300.

Annila, A. and Kuismanen, E. (2009). Natural hierarchy emerges from energy dispersal. BioSystems, 95(3):227-233.

Arendt, D., Denes, A. S., Jékely, G., and Tessmar-Raible, K. (2008). The evolution of nervous system centralization. Philosophical Transactions of the Royal Society B: Biological Sciences, 363(1496):1523-1528.

Ariga, K., Brunello, G., Ohkusa, Y., and Nishiyama, Y. (1992). Corporate hierarchy, promotion, and firm growth: Japanese internal labor market in transition. Journal of the Japanese and International Economies, 6(4):440-471.

Arnsperger, C. and Varoufakis, Y. (2006). What is neoclassical economics? the three axioms responsible for its theoretical oeuvre, practical irrelevance and, thus, discursive power. Panoeconomicus, 53(1):5-18.

Audas, R., Barmby, T., and Treble, J. (2004). Luck, effort, and reward in an organizational hierarchy. Journal of Labor Economics, 22(2):379-395.

Axtell, R. L. (2001). Zipf distribution of US firm sizes. Science, 293:1818-1820.

Backhouse, R. E. (2010). The puzzle of modern economics: Science or ideology? Cambridge University Press.

Baker, G., Gibbs, M., and Holmstrom, B. (1993). Hierarchies and compensation: A case study. European Economic Review, 37(2-3):366-378.

Bell, B. and Van Reenen, J. (2012). Firm performance and wages: evidence from across the corporate hierarchy. CEP Discussion paper, 1088.

Bendix, R. (1998). Max Weber: an intellectual portrait, volume 2. Psychology Press, London. 
Bichler, S. and Nitzan, J. (2020). Growing through sabotage: Energizing hierarchical power. Review of Capital as Power, 1(5):1-78.

Boltzmann, L. (2011). Populare Schriften. SEVERUS Verlag.

Brown, J. H., Burnside, W. R., Davidson, A. D., DeLong, J. P., Dunn, W. C., Hamilton, M. J., Mercado-Silva, N., Nekola, J. C., Okie, J. G., Woodruff, W. H., and Zuo, W. (2011). Energetic limits to economic growth. BioScience, 61(1):1926.

Brown, P. G. and Timmerman, P. (2015). Ecological economics for the anthropocene: An emerging paradigm. Columbia University Press, New York.

Carter, S. B., Gartner, S. S., Haines, M. R., Olmstead, A. L., Sutch, R., and Wright, G. (2006). Historical statistics of the United States: millennial edition, volume 3. Cambridge: Cambridge University Press.

Chaisson, E. (2002). Cosmic Evolution: The Rise of Complexity in Nature. Harvard University Press, Cambridge, Mass.

Chaisson, E. (2005). Non-equilibrium thermodynamics in an energy-rich world. In Kleidon, A. and Lorenz, R., editors, Non-equilibrium Thermodynamics and the Production of Entropy: Life, Earth, and Beyond, pages 21-31. Springer, New York.

Collins, A. (2014). The divinity of the pharaoh in Greek sources. The Classical Quarterly, 64(2):841-844.

Council, S. V. (1964). Lumen gentium. Dogmatic Constitution on the Church, 21:5-71.

Dawkins, R. (1976). The Selfish Gene. Oxford University Press, Oxford.

Dohmen, T. J., Kriechel, B., and Pfann, G. A. (2004). Monkey bars and ladders: The importance of lateral and vertical job mobility in internal labor market careers. Journal of Population Economics, 17(2):193-228.

Dunbar, R. I. (1993). Coevolution of neocortical size, group size and language in humans. Behavioral and Brain Sciences, 16(04):681-694.

Dunbar, R. I. (2013). What makes the Neolithic so special? NEO-LITHICS, 13.

Eriksson, T. (1999). Executive compensation and tournament theory: Empirical tests on Danish data. Journal of Labor Economics, 17(2):262-280. 
Feynman, R. P., Leighton, R. B., and Sands, M. (2013). The Feynman Lectures on Physics, Desktop Edition Volume I, volume 1. Basic books.

Fichtner, J., Heemskerk, E. M., and Garcia-Bernardo, J. (2017). Hidden power of the big three? passive index funds, re-concentration of corporate ownership, and new financial risk. Business and Politics, 19(2):298-326.

Figgis, J. N. (1922). The divine right of kings. University Press.

Fisher, F. (1987). Adjustment processes and stability. In Milgate, M. and Newman, P., editors, The New Palgrave: A Dictionary of Economics, volume 26-9. Palgrave Macmillan, London.

Fix, B. (2017). Energy and institution size. PLOS ONE, 12(2):e0171823.

Fix, B. (2018). Hierarchy and the power-law income distribution tail. Journal of Computational Social Science, 1(2):471-491.

Fix, B. (2019a). The aggregation problem: Implications for ecological and biophysical economics. BioPhysical Economics and Resource Quality, 4(1):1.

Fix, B. (2019b). An evolutionary theory of resource distribution. Real-World Economics Review, (90):65-97.

Fix, B. (2019c). Personal income and hierarchical power. Journal of Economic Issues, 53(4):928-945.

Fix, B., Nitzan, J., and Bichler, S. (2019). Real GDP: the flawed metric at the heart of macroeconomics. Real-world economics review, (88):51-59.

Friedman, M. (1962). Capitalism and Freedom. University of Chicago press, Chicago.

Friedman, M. and Friedman, R. (1990). Free to choose: A personal statement. Houghton Mifflin Harcourt.

Gaffeo, E., Gallegati, M., and Palestrini, A. (2003). On the size distribution of firms: additional evidence from the G7 countries. Physica A: Statistical Mechanics and its Applications, 324(1-2):117-123.

Gelfand, M. (2019). Rule Makers, Rule Breakers: Tight and Loose Cultures and the Secret Signals That Direct Our Lives. Scribner. 
Gelfand, M., Jackson, J. C., Pan, X., Nau, D., Dagher, M. M., Lange, P., and Chiu, C.-y. (2020). The importance of cultural tightness and government efficiency for understanding covid-19 growth and death rates. Preprint]. PsyArXiv. https://doi. org/10.31234/osf. io/m7f8a.

Gelfand, M. J., Bhawuk, D. P., Nishii, L. H., and Bechtold, D. J. (2004). Individualism and collectivism. Culture, leadership, and organizations: The GLOBE study of 62 societies, pages 437-512.

Georgescu-Roegen, N. (1971). The entropy law and the economic process. Harvard University Press, Cambridge, MA.

Giampietro, M., Mayumi, K., and Sorman, A. (2012). The Metabolic Pattern of Societies: Where Economists Fall Short. Routledge, New York.

Gillespie, C. S. (2014). Fitting heavy tailed distributions: the poweRlaw package. arXiv preprint arXiv:1407.3492, pages 1-16.

Glattfelder, J. B. and Battiston, S. (2009). Backbone of complex networks of corporations: The flow of control. Physical Review E, 80(3):036104.

Gowdy, J. and Krall, L. (2013). The ultrasocial origin of the anthropocene. Ecological Economics, 95:137-147.

Gowdy, J. and Krall, L. (2014). Agriculture as a major evolutionary transition to human ultrasociality. Journal of Bioeconomics, 16(2):179-202.

Grosberg, R. K. and Strathmann, R. R. (2007). The evolution of multicellularity: A minor major transition? Annual Review of Ecology, Evolution, and Systematics, 38(1):621-654.

Grund, C. (2005). The wage policy of firms: comparative evidence for the US and Germany from personnel data. The International Journal of Human Resource Management, 16(1):104-119.

Hatton, I. A., Dobson, A. P., Storch, D., Galbraith, E. D., and Loreau, M. (2019). Linking scaling laws across eukaryotes. Proceedings of the National Academy of Sciences, 116(43):21616-21622.

Hayden, B. (2001). Richman, poorman, beggarman, chief: The dynamics of social inequality. In Archaeology at the Millennium, pages 231-272. Springer. 
Heilbroner, R. (1990). Economics as ideology. In Economics as discourse, pages 101-128. Springer.

Herbert, S. (1962). The architecture of complexity. Proceedings of the American Philosophical Society, 106(6):467-482.

Heyman, F. (2005). Pay inequality and firm performance: evidence from matched employer-employee data. Applied Economics, 37(11):1313-1327.

Hodgson, G. M. (2019). Is There a Future for Heterodox Economics?: Institutions, Ideology and a Scientific Community. Edward Elgar Publishing.

Hofstede, G., Hofstede, G. J., and Minkov, M. (2010). Cultures and Organizations: Software of the Mind. McGraw-Hill, New York, 3rd edition.

Hoover, K. R. (2003). Economics as ideology: Keynes, Laski, Hayek, and the creation of contemporary politics. Rowman \& Littlefield Publishers.

Hunt, E. K. (2011). History of Economic Thought: A Critical Perspective. M.E. Sharpe, Armonk, N.Y.

Hunt, E. K. (2016). Property and Prophets: The Evolution of Economic Institutions and Ideologies. Routledge, New York.

Keen, S. (2001). Debunking Economics: The Naked Emperor of the Social Sciences. Zed Books, New York.

Keen, S. and Standish, R. (2006). Profit maximization, industry structure, and competition: A critique of neoclassical theory. Physica A: Statistical Mechanics and its Applications, 370(1):81-85.

Kondepudi, D. and Prigogine, I. (1998). Modern Thermodynamics: from Heat Engines to Dissipative Structures. John Wiley \& Sons, Chichester.

Lakatos, I. (1976). Falsification and the methodology of scientific research programmes. In Can theories be refuted?, pages 205-259. Springer.

Lane, N. (2011). Energetics and genetics across the prokaryote-eukaryote divide. Biology direct, 6(1):35.

Lane, N. (2014). Bioenergetic constraints on the evolution of complex life. Cold Spring Harbor perspectives in biology, 6(5):a015982. 
Lane, N. (2015). The vital question: energy, evolution, and the origins of complex life. WW Norton \& Company, New York.

Lane, N. and Martin, W. (2010). The energetics of genome complexity. Nature, 467(7318):929-934.

Lee, F. and Keen, S. (2004). The incoherent emperor: a heterodox critique of neoclassical microeconomic theory. Review of Social Economy, 62(2):169-199.

Leibenstein, H. (2013). Inside the firm. Harvard university press.

Leonard, J. S. (1990). Executive pay and firm performance. Industrial and Labor Relations Review, 43(3):13-28.

Lewis, B. E. and Churchill, B. E. (2008). Islam: The religion and the people. Pearson Prentice Hall.

Lima, F. (2000). Internal labor markets: A case study. FEUNL Working Paper, 378.

López-García, P., Eme, L., and Moreira, D. (2017). Symbiosis in eukaryotic evolution. Journal of theoretical biology, 434:20-33.

López-García, P. and Moreira, D. (1999). Metabolic symbiosis at the origin of eukaryotes. Trends in biochemical sciences, 24(3):88-93.

Lydall, H. F. (1959). The distribution of employment incomes. Econometrica: Journal of the Econometric Society, 27(1):110-115.

Main, B. G., O'Reilly III, C. A., and Wade, J. (1993). Top executive pay: Tournament or teamwork? Journal of Labor Economics, 11(4):606-628.

Mankiw, N. G. (2012). Principles of microeconomics. South-Western, Cengage Learning, Mason, $\mathrm{OH}$, 6th edition.

Marglin, S. A. (1974). What do bosses do? the origins and functions of hierarchy in capitalist production. Review of radical political economics, 6(2):60-112.

Margulis, L. (1981). Symbiosis in cell evolution: Life and its environment on the early earth. W H Freeman \& Co.

Martin, D. A. (1990). Economics as ideology: on making "the invisible hand" invisible. Review of Social Economy, 48(3):272-287. 
Marx, K. (1867). Capital, Volume I. Harmondsworth: Penguin/New Left Review.

Marx, K. and Engels, F. (1967). The communist manifesto (1848). Karl Marx: Selected Writings, pages 157-186.

Mas-Colell, A., Whinston, M. D., Green, J. R., et al. (1995). Microeconomic theory, volume 1. Oxford University Press, New York.

McNeill, J. R. and Engelke, P. (2016). The great acceleration: An environmental history of the Anthropocene since 1945. Harvard University Press.

Means, G. C. (1992). The Heterodox Economics of Gardiner C. Means: A Collection. ME Sharpe.

Mirowski, P. (1991). More Heat Than Light: Economics as Social Physics, Physics as Nature's Economics. Cambridge Univ Pr.

Mones, E., Vicsek, L., and Vicsek, T. (2012). Hierarchy measure for complex networks. PloS one, 7(3):e33799.

Morais, F. and Kakabadse, N. K. (2014). The corporate Gini index (cgi) determinants and advantages: Lessons from a multinational retail company case study. International Journal of Disclosure and Governance, 11(4):380-397.

Mueller, H. M., Ouimet, P. P., and Simintzi, E. (2016). Within-firm pay inequality. SSRN Working Paper.

Nedelcu, A. M. (2020). The evolution of multicellularity and cancer: views and paradigms. Biochemical Society Transactions, 48(4):1505-1518.

Nepusz, T. and Vicsek, T. (2013). Hierarchical self-organization of noncooperating individuals. Plos one, 8(12).

Nitzan, J. and Bichler, S. (2009). Capital as Power: A Study of Order and Creorder. Routledge, New York.

Nowak, M. A., Tarnita, C. E., and Wilson, E. O. (2010). The evolution of eusociality. Nature, 466(7310):1057.

O’Donnell, S. (1998). Reproductive caste determination in eusocial wasps (hymenoptera: Vespidae). Annual review of entomology, 43(1):323-346.

Okasha, S. (2005). Multilevel selection and the major transitions in evolution. Philosophy of science, 72(5):1013-1025. 
Pennisi, E. (2004). The birth of the nucleus. Science, 305(5685):766-768.

Popper, K. (1959). The Logic of Scientific Discovery. Hutchinson \& Co., New York.

Pullen, J. (2009). The marginal productivity theory of distribution: a critical history. Routledge, London.

Rajan, R. G. and Wulf, J. (2006). The flattening firm: Evidence from panel data on the changing nature of corporate hierarchies. The Review of Economics and Statistics, 88(4):759-773.

Richerson, P. J. and Boyd, R. (1998). The evolution of human ultra-sociality. In Indoctrinability, ideology, and warfare: Evolutionary perspectives, pages 71-95. Berghahn Books, New York.

Robinson, J. (1962). Economic philosophy. Aldine Pub. Co., Chicago.

Sagan, L. (1967). On the origin of mitosing cells. Journal of theoretical biology, 14(3):225-274.

Samuels, W. J. (1992). Ideology in economics. In Essays on the Methodology and Discourse of Economics, pages 233-248. Springer.

Samuelson, P. A. (1971). Understanding the Marxian notion of exploitation: a summary of the so-called transformation problem between Marxian values and competitive prices. Journal of Economic Literature, 9(2):399-431.

Sanderson, C. and Curtin, R. (2016). Armadillo: a template-based C++ library for linear algebra. Journal of Open Source Software, 1(2):26.

Schrodinger, E. (1992). What is life?: With mind and matter and autobiographical sketches. Cambridge University Press.

Shimoji, H., Abe, M. S., Tsuji, K., and Masuda, N. (2014). Global network structure of dominance hierarchy of ant workers. Journal of the Royal Society Interface, 11(99):20140599.

Simon, H. A. (1957). The compensation of executives. Sociometry, 20(1):32-35.

Simon, H. A. (1991). The architecture of complexity. In Facets of systems science, pages 457-476. Springer.

Smith, A. (1776). An Inquiry into the Nature and Causes of the Wealth of Nations. A. and C. Black, Edinburgh. 
Smith, J. M. and Szathmary, E. (1997). The major transitions in evolution. Oxford University Press.

Sober, E. and Wilson, D. S. (1999). Unto others: The evolution and psychology of unselfish behavior. Harvard University Press.

Söderbaum, P. (2008). Economics as ideology. In Fullbrook, E., editor, Pluralist Economics, pages 117-127. Zed Books London.

Sprules, W. G. and Barth, L. E. (2016). Surfing the biomass size spectrum: some remarks on history, theory, and application. Canadian Journal of Fisheries and Aquatic Sciences, 73(4):477-495.

Sraffa, P. (1960). Production of commodities by means of commodities: Prelude to a critique of economic theory. Cambridge University Press, London.

Steffen, W., Broadgate, W., Deutsch, L., Gaffney, O., and Ludwig, C. (2015). The trajectory of the anthropocene: the great acceleration. The Anthropocene Review, 2(1):81-98.

Stewart, J. E. (2019a). The origins of life: the managed-metabolism hypothesis. Foundations of Science, 24(1):171-195.

Stewart, J. E. (2019b). The trajectory of evolution and its implications for humanity. Journal of Big History, 3:141-155.

Stewart, J. E. (2020). Towards a general theory of the major cooperative evolutionary transitions. Biosystems, 198:104237.

Strauss, G. (1957). The changing role of the working supervisor. The Journal of Business, 30(3):202-211.

Tao, H.-L. and Chen, I.-T. (2009). The level of technology employed and the internal hierarchical wage structure. Applied Economics Letters, 16(7):739744.

Treble, J., Van Gameren, E., Bridges, S., and Barmby, T. (2001). The internal economics of the firm: further evidence from personnel data. Labour Economics, $8(5): 531-552$.

Turchin, P. (2010). Warfare and the evolution of social complexity: a multilevelselection approach. Structure and Dynamics, 4(3). 
Turchin, P. (2013). The puzzle of human ultrasociality: How did large-scale complex societies evolve? In Cultural Evolution: Society, Technology, Language, and Religion, pages 61-74. MIT Press, Cambridge, MA.

Turchin, P. (2016). Ultrasociety: How 10,000 Years of War Made Humans the Greatest Cooperators on Earth. Beresta Books, Chaplin, Connecticut.

Turchin, P. and Gavrilets, S. (2009). Evolution of complex hierarchical societies. Social Evolution and History, 8(2):167-198.

Veblen, T. (1898). Why is economics not an evolutionary science? The quarterly journal of economics, 12(4):373-397.

Vitali, S., Glattfelder, J. B., and Battiston, S. (2011). The network of global corporate control. PloS one, 6(10):e25995.

West, S. A., Fisher, R. M., Gardner, A., and Kiers, E. T. (2015). Major evolutionary transitions in individuality. Proceedings of the National Academy of Sciences, 112(33):10112-10119.

Wilson, D. S. (1997). Altruism and organism: Disentangling the themes of multilevel selection theory. The American Naturalist, 150(S1):s122-S134.

Wilson, D. S. (2010). Darwin's cathedral: Evolution, religion, and the nature of society. University of Chicago Press.

Wilson, D. S. (2015). Does altruism exist? Culture, genes, and the welfare of others. Yale University Press.

Wilson, D. S. and Gowdy, J. M. (2015). Human ultrasociality and the invisible hand: foundational developments in evolutionary science alter a foundational concept in economics. Journal of Bioeconomics, 17(1):37-52.

Wilson, D. S. and Sober, E. (1989). Reviving the superorganism. Journal of theoretical Biology, 136(3):337-356.

Wilson, D. S. and Sober, E. (1994). Reintroducing group selection to the human behavioral sciences. Behavioral and brain sciences, 17(4):585-608.

Wilson, D. S., Van Vugt, M., and O'Gorman, R. (2008). Multilevel selection theory and major evolutionary transitions: Implications for psychological science. Current Directions in Psychological Science, 17(1):6-9. 
Wilson, D. S. and Wilson, E. O. (2007). Rethinking the theoretical foundation of sociobiology. The Quarterly review of biology, 82(4):327-348.

Wilson, E. O. and Hölldobler, B. (2005). Eusociality: origin and consequences. Proceedings of the National Academy of Sciences, 102(38):13367-13371.

Wood, A. T. (1995). Limits to Autocracy: From Sung Neo-Confucianism to a Doctrine of Political Rights. University of Hawaii Press. 